\title{
Shaking Table Testing for Masonry Infill walls: Unreinforced vs. Reinforced solutions
}

\author{
Paulo B. Lourenço ${ }^{1}$, João M. Leite ${ }^{1}$, Manuel F. Paulo-Pereira ${ }^{1}$, \\ A. Campos-Costa ${ }^{2}$, P. X. Candeias ${ }^{2}$, Nuno Mendes ${ }^{1}$ \\ ${ }^{1}$ ISISE, Department of Civil Engineering, University of Minho, Guimarães, Portugal \\ ${ }^{2}$ NESDE, National Laboratory for Civil Engineering, Lisbon, Portugal
}

\begin{abstract}
Several factors influence the behaviour of infilled frames, which have been a subject of research in the past with moderate success. The new generation of European design standards imposes the need to prevent brittle collapse of the infills and makes the structural engineer accountable for this requirement, yet it fails to provide sufficient information for masonry infills design. Therefore, the present work aims at understanding the seismic behaviour of masonry infill walls within reinforced concrete frames, using both unreinforced and reinforced solutions (bed joint reinforcement and reinforced plaster). For this purpose, three reinforced concrete buildings with different infill solutions were constructed at a scale of 1:1.5, all with the same geometry, and were tested on the shaking table of the National Laboratory for Civil Engineering, Portugal. All solutions performed adequately for the design earthquake, with no visible damage. Still, the experimental tests show that the double leaf unreinforced infill walls underperformed during a large earthquake, collapsing out-of-plane by rotating as rigid bodies with multiple configurations. Also the reinforced concrete buildings collapsed, due to the adverse interaction with the infill walls. The infill walls with bed joint reinforcement and reinforced plaster did not collapse out-of-plane, due to their connection to the concrete frame, which is an essential requirement.
\end{abstract}

\section{Keywords}

Masonry infills, reinforced concrete frame, bed joint reinforcement, reinforced plaster, shaking table tests, earthquake engineering. 


\section{Introduction}

Even if the study of masonry infilled frames started several decades ago, there are a large number of factors, not yet fully understood, that influence their behaviour, such as mechanical properties of the materials, aspect ratio, boundary conditions, presence of reinforcement or presence of openings. The role of the infill walls on the global performance of frame structures subjected to seismic action is mostly clear at this point, see e.g. [1], as well as the design situations that need to be avoided, so that the influence of the infill is either positive or neutral [2]. The demonstration that further studies are still needed is the behaviour observed during several recent earthquakes, which can be analysed from two different perspectives: i) life safety (Ultimate Limit State), since the infills walls often collapse out-of-plane, see Figure 1, even for recent structures designed using the last generation of design codes; ii) economy (Serviceability Limit State), since up to $80 \%$ of the full cost of buildings can be needed to reconstruct non-structural elements, including masonry infills, finishings, false ceilings, doors, windows and installations (water, electricity, gas, etc.) [3].
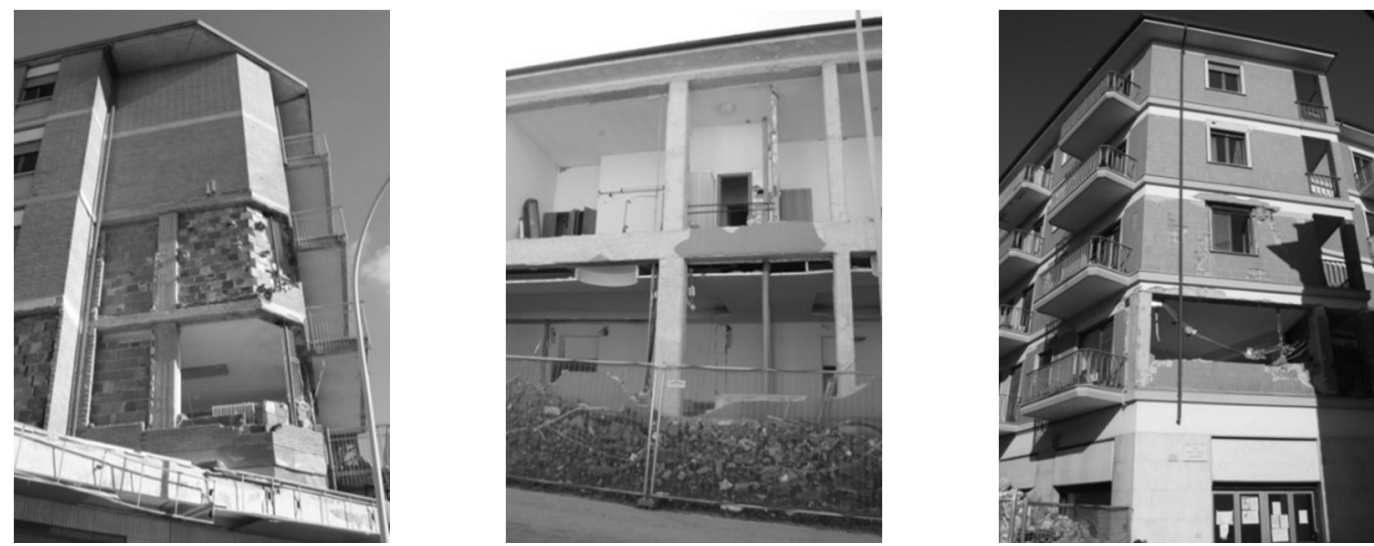

Figure 1: Partial and complete out-of-plane collapses of infill walls during the L'Aquila earthquake (2009), Italy, which is a recurring phenomenon.

The present work addresses the seismic behaviour of unreinforced and reinforced clay brick masonry infills, built within reinforced concrete frames subjected to seismic actions. In order to evaluate the infill solutions, three buildings were tested on the shaking table of the National Laboratory for Civil Engineering, Portugal, at a scale of 1:1.5. The specimens were subjected to increasing levels of horizontal accelerations, in the two orthogonal main directions. These tests allowed evaluating the seismic performance of the infill walls and the seismic performance of the reinforced concrete (RC) structure and the interaction of the different infill solutions with the RC structure.

One building represents the standard Portuguese construction in the last three decades, designed using the previous generation of standards [4,5] and with unreinforced double leaf enclosure infill walls. The other two buildings represent the present and, possibly, future construction, with a RC structure designed using Eurocodes EC2 [6] and EC8 [7], and with two reinforced enclosure infill solutions, namely a single leaf with bed joint reinforcement and a single leaf with reinforced plaster. EC8 imposes that appropriate measures are taken to avoid brittle failure and premature disintegration of the infill walls, as well as the partial or total out-of-plane collapse. The code also defines that in-plane and out-of-plane collapse can be prevented using light wire meshes well anchored on one face of the wall, wall ties fixed to the columns and cast into the bedding planes of the masonry, and concrete posts and belts across the panels and through the full thickness of the wall. 


\section{Shaking table test: setup and prototypes}

The objective of this work is to test the complete structure, allowing to characterize the interplay of the response of all components. Physical limitations (maximum dimensions and payload capacity) impose, in most cases, the use of scaled models in shaking table tests. Scaled models require similitude laws, which add complexity to the construction and test setup, as it is necessary to correctly simulate: i) the geometry; ii) the stress-strain relationship of the materials; iii) the mass and gravity forces; iv) the initial conditions and the boundary conditions [8].

Very small scales provide extreme construction challenges. Obtaining adequate stress-strain relationships of the materials can be a complex task [9] since they have to be fulfilled throughout different stress or strain levels, rates, gradients, etc. For very small scales it is not uncommon to use different materials in the models. The mass and gravity forces are addressed, respectively, by the Cauchy and Froude similitude laws [8]. The former is adequate for phenomena in which the restoring forces are derived from the stress-strain constitutive relationships and the elastic restoring forces. The latter is adequate for phenomena in which the gravity forces are important, being the Froude value the ratio between inertia forces and gravity forces. The use of both laws simultaneously, as done in this work, is the obvious choice to more accurately replicate the dynamic behaviour of structures, particularly when strongly non-linear behaviour is expected. The adopted scaling relations are described in Table 1.

\subsection{Geometry and materials}

The first step in the present experimental program was the definition of the geometry and the building solutions of the prototypes. A geometry survey was done elsewhere to define the average height and length of the frames in Portugal [10]. The resulting geometry was incorporated in a building with a two storey single bay frame in one direction and a two storey double bay frame in the other direction. Here, the models were designed at a reduced scale of 1:1.5, meaning that reduced loads were applied to a model with the geometry also reduced, see Figure 2.

Three different models, see Table 2, were idealized. Model 1 represents the built heritage in the last three decades, while models 2 and 3 represent likely future solutions. The chosen class for concrete and rebar reflects this distinction, as lower classes were used in model 1 (C20/25 and S400) and higher classes in models 2 and 3 (C30/37 and S500). In model 1, all columns had $4 \phi 16$ as longitudinal reinforcement, except the centre columns in East/West façades and $2^{\text {nd }}$ storey with $4 \phi 12$, with stirrups $\phi 6 / / 0.15 \mathrm{~m}$. In models 2 and 3, besides using a higher class steel, also the centre columns in the first storey had only $4 \phi 12$ as longitudinal reinforcement, keeping the rest unchanged. Full detailing of the beams reinforcement is provided in [10], where all constructions drawings are provided. The mortar used for the bed joints and plaster was pre-batched, with a M5 class. Further details on mechanical properties can be found in [10]. The design loads were reduced using the similitude law relations as given in Table 3.

Full details of the mechanical properties of the materials used can be found in [10] and [11]. For the concrete, compressive tests according to EN 12390-3 and flexural tests according to EN 12390-5 were carried for each model and concrete batch, at 28 days. The average compressive strength obtained was $29.5,36.8$ and $44.8 \mathrm{MPa}$, for models 1,2 and 3 , respectively. The average flexural strength obtained was $4.0,4.3$ and $4.9 \mathrm{MPa}$, for models 1, 2 and 3, respectively. The steel adopted in the model was not characterized in 
the laboratory, even if the class is known. For the mortar, compressive and flexural tests according to EN 1015-11 were carried out at 28 days, providing an average compressive strength and flexural strength of 4.4 and $1.7 \mathrm{MPa}$, respectively. The adopted clay brick is a hollow clay tile with an average compressive according to EN 772-1 of $4.1 \mathrm{MPa}$ (only bricks with a width of $0.15 \mathrm{~m}$ were tested). Finally, for the masonry, panels have been tested under uniaxial compression, flexure and shear, according to the applicable European Standards [10]. These panels have four configurations: (a) masonry alone; (b) masonry with rendering; (c) masonry with rendering and bed joint reinforcement; (d) masonry with reinforced rendering.

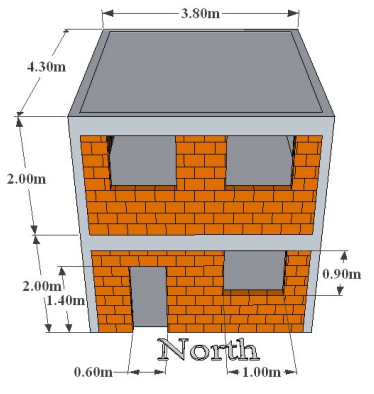

(a)

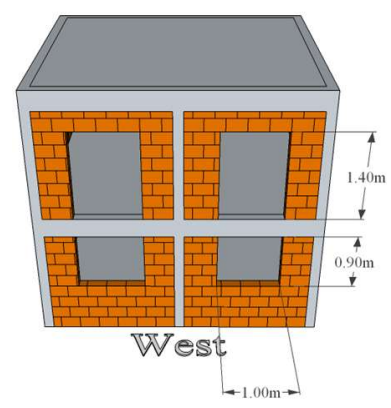

(b)

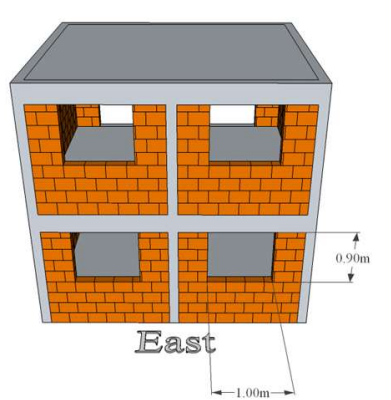

(c)

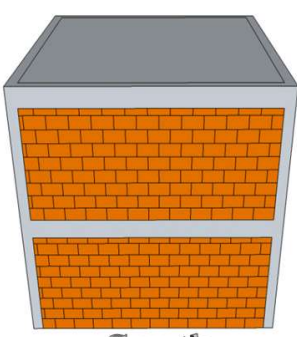

South

(d)

Figure 2: Geometry of the model: (a) North; (b) West; (c) East; (d) South.

Table 1: Cauchy-Froude similitude law.

\begin{tabular}{|c|c|c|c|}
\hline Parameter & Scale Factor & Parameter & Scale Factor \\
\hline Length (L) & $L_{p} / L_{m}=\lambda$ & Mass (m) & $\lambda^{2}$ \\
\hline Modulus of elasticity ( E ) & $E_{p} / E_{m}=1$ & Weight (w) & $\lambda^{2}$ \\
\hline Specific mass ( $\rho)$ & $\rho_{p} / \rho_{m}=\lambda^{-1}$ & Force (F) & $\lambda^{2}$ \\
\hline Area (A) & $\lambda^{2}$ & Moment (M) & $\lambda^{3}$ \\
\hline Volume (V) & $\lambda^{3}$ & Stress ( $\tau$ ) & 1 \\
\hline Displacement (d) & $\lambda$ & Strain $(\varepsilon)$ & 1 \\
\hline Velocity (v) & $\lambda^{1 / 2}$ & Time (t) & $\lambda^{1 / 2}$ \\
\hline Acceleration (a) & 1 & Frequency (f) & $\lambda^{-1 / 2}$ \\
\hline
\end{tabular}

Table 2: Description of the tested models.

\begin{tabular}{|c|c|c|c|c|}
\hline $\begin{array}{c}\text { Model } \\
\text { number }\end{array}$ & $\begin{array}{c}\text { Design } \\
\text { standards }\end{array}$ & $\begin{array}{c}\text { Concrete } \\
\text { class }\end{array}$ & $\begin{array}{c}\text { Rebar } \\
\text { class }\end{array}$ & Infill solution \\
\hline 1 & RSA/REBAP & $\mathrm{C} 20 / 25$ & $\mathrm{~S} 400$ & $\begin{array}{c}\text { Double leaf clay brick } \\
\text { unreinforced wall }\end{array}$ \\
\hline 2 & $\mathrm{EC} 2 / \mathrm{EC} 8$ & $\mathrm{C} 30 / 37$ & $\mathrm{~S} 500$ & $\begin{array}{c}\text { Single leaf clay brick wall with bed joint } \\
\text { reinforcement every two joints }\end{array}$ \\
\hline 3 & $\mathrm{EC} 2 / \mathrm{EC} 8$ & $\mathrm{C} 30 / 37$ & $\mathrm{~S} 500$ & $\begin{array}{c}\text { Single leaf clay brick wall with reinforced } \\
\text { plaster on both sides }\end{array}$ \\
\hline
\end{tabular}

Table 3: Design loads of the models already reduced at scale of 1:1.5.

\begin{tabular}{|c|c|c|c|}
\hline Load & Description & Self-weight & Model \\
\hline Slabs & reinforced concrete slab (thickness $=0.12 \mathrm{~m})$ & $1.07 \mathrm{KN} / \mathrm{m}^{2}$ & All \\
\hline Infill walls & $\begin{array}{c}\text { mortar render }(1.5 \mathrm{~cm})+\text { clay cavity masonry } \\
(9 \mathrm{~cm}+2 \mathrm{~cm}+7 \mathrm{~cm})+\text { gypsum plaster }(1.5 \mathrm{~cm})\end{array}$ & $3.74 \mathrm{KN} / \mathrm{m}$ & Model 1 \\
\hline Infill walls & $\begin{array}{c}\text { mortar render }(1.5 \mathrm{~cm})+\text { clay masonry units } \\
(11 \mathrm{~cm})+\text { gypsum plaster }(1.5 \mathrm{~cm})\end{array}$ & $2.11 \mathrm{KN} / \mathrm{m}^{2}$ & Model 2 and 3 \\
\hline
\end{tabular}




\subsection{Infill solutions}

The infills of model 1 were an unreinforced double leaf clay brick wall with a cavity, see Figure 3. Horizontally perforated units were used and the outer leaf partially hanging from the RC frame. The outer surface of the RC frame was covered with a thin clay brick unit to avoid thermal bridges. The inner leaf had a gypsum plaster, while the outer leaf had a mortar rendering.

The infills of model 2 were a single leaf clay brick wall with bed joint reinforcement every two bed joints, see Figure 4. The leaf was completely within the RC frame plane (as an external thermal insulation system will be required) with an internal gypsum plaster and an external mortar rendering. Again, horizontally perforated units were used. The bed joint reinforcement was a truss Bekaert Murfor RND.4/100, with longitudinal bars 100 $\mathrm{mm}$ apart and $4 \mathrm{~mm}$ diameter. The bed joint reinforcement was connected to the $\mathrm{RC}$ frame through steel bars at both ends, see Figure 4 (c). These bars are $30 \mathrm{~cm}$ long bars with 6 $\mathrm{mm}$ diameter and inserted in the $\mathrm{RC}$ columns during the formwork construction. The adopted amount of bed joint reinforcement is the minimum requested EC2 [6] to help control cracking, to provide ductility or to enhance resistance to lateral loads $(0.03 \%)$, whereas the reinforced concrete bars have been designed to withstand the maximum force in the bed joint reinforcement.

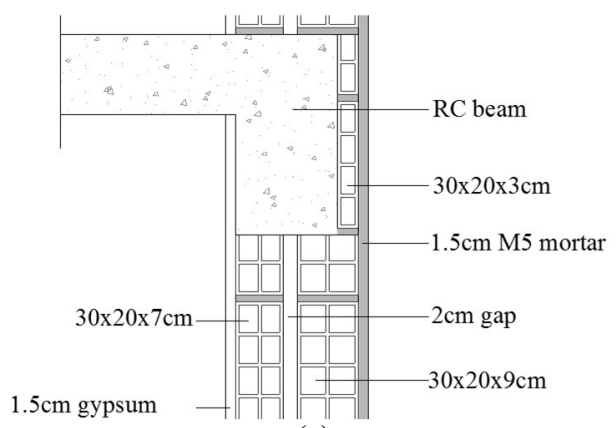

(a)

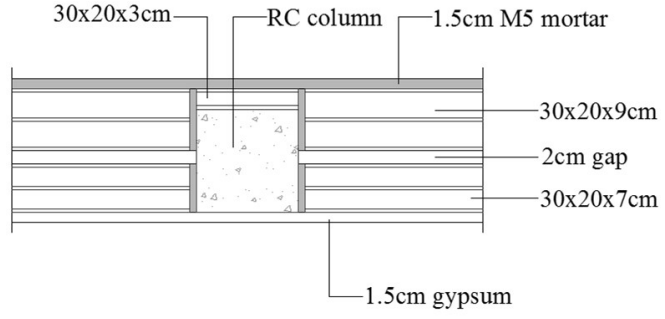

(b)

Figure 3: Double leaf clay brick unreinforced infill walls of Model 1, scaled. Details at: (a) RC beam (elevation section); (b) RC column (plan section).

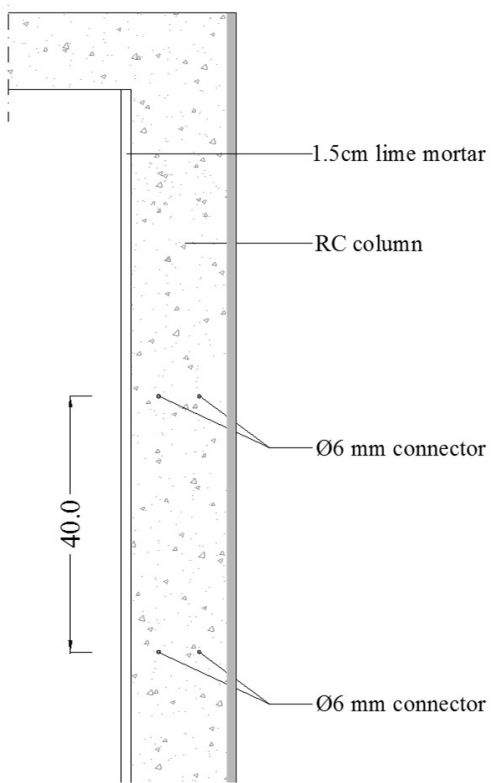

(a)

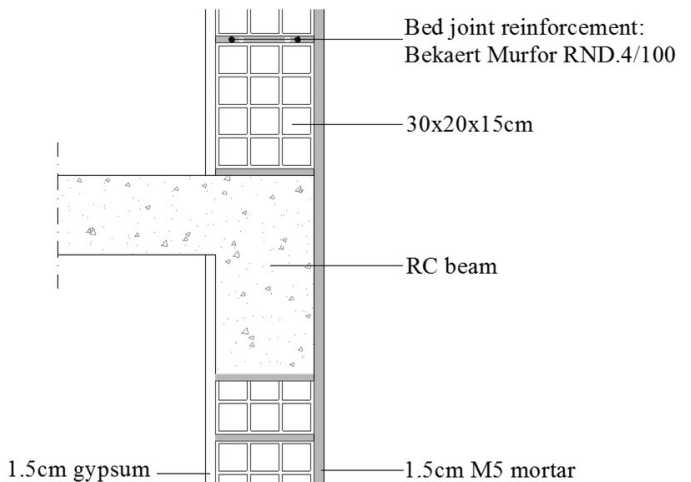

(b)

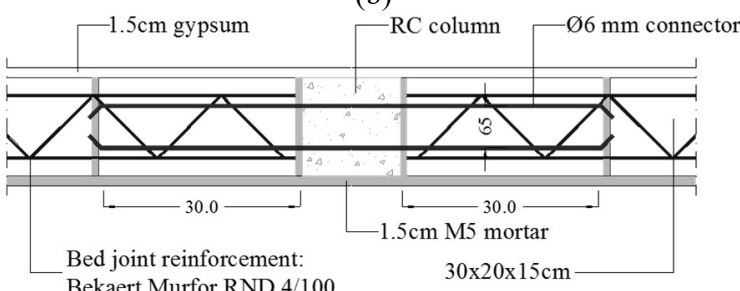

(c)

Figure 4: Single leaf clay brick infill walls with bed joint reinforcement from Model 2, scaled: (a) wall section; (b) detail at the RC beam (elevation section); (c) detail at the RC column (plan section). 
The infills of model 3 were also made with single leaf clay brick masonry, see Figure 5. Instead of bed joint reinforcement, reinforced plaster was used on both wall faces, with a grid Bekaert Armanet $\phi 1.05 \mathrm{~mm} 12.7 \times 12.7 \mathrm{~mm}$ nailed to the RC frame using Hilti XM8H10-37-P8 nails, together with a gun and Hilti shot powder actuated tools. Similar nails should have been used to nail the grid to the infill wall but were replaced by the connectors of the additional masses needed to respect the similitude law chosen. The adopted amount of grid reinforcement is in between the minimum requested EC2 [6] to help control cracking, to provide ductility or to enhance resistance to lateral loads $(0.03 \%)$ and to enhance the strength in the plane of the member $(0.05 \%)$.

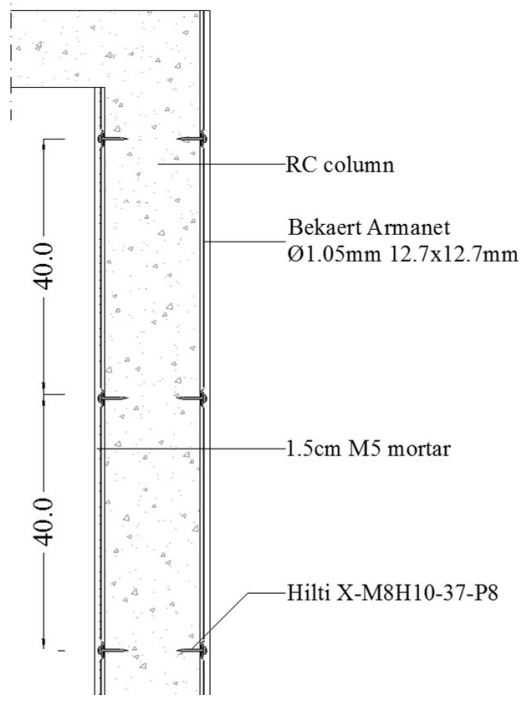

(a)

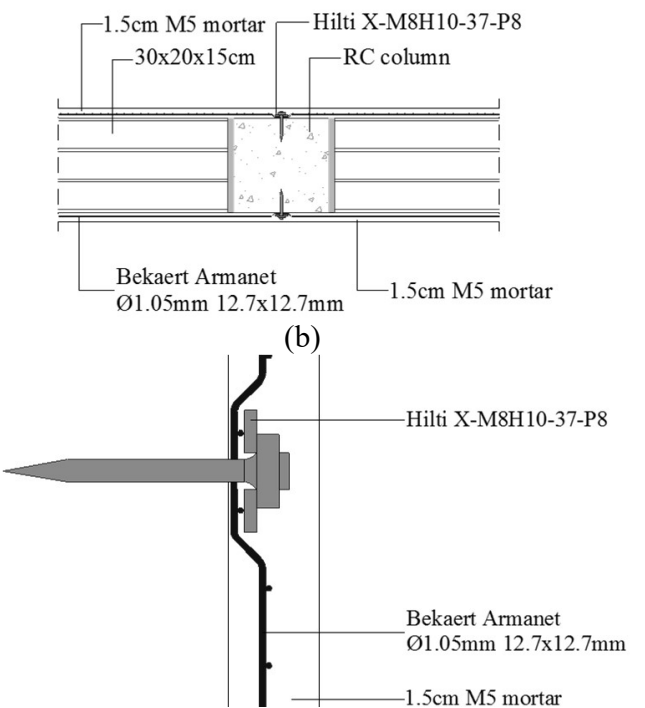

(c)

Figure 5: Single leaf clay brick infill walls with reinforced plaster from Model 3, scaled: (a) wall section; (b) detail at the RC column (plan section); (c) detail of the Hilti X-M8H10-37-P8 connectors (elevation).

\section{Shaking table input and acquisition setup}

\subsection{Input}

Shaking table tests can be performed by introducing an earthquake record from past events, usually scaled, or an artificial accelerogram. In the present experimental work, eight artificial accelerograms were generated using LNEC-SPA [12] in order to obtain four stages of the shaking table tests, with increasing amplitude, see Table 4. The accelerograms of the first three stages were adapted to the response spectra (damping ratio equal to 5\%) of each damage limit state defined in part 3 of EC8 (far-field): Damage Limitation (DL 225 YRP); Significant Damage (SD 475 YRP); Near Collapse (NC 2475 YRP). Here, YRP are the years of the return period. A last stage was defined as the maximum capacity of the table in terms of velocity, given the size and mass of the model, and it corresponds to 4574 YRP.

Table 4: Adopted shaking table test sequence of inputs.

\begin{tabular}{|c|c|c|}
\hline Stage & Identification & Description \\
\hline \multirow{2}{*}{1} & DI 0 & Initial dynamic identification test \\
\cline { 2 - 3 } & DL & Deismic test based on Damage Limitation $-225 \mathrm{YRP}\left(\mathrm{PGA}=1.5 \mathrm{~m} / \mathrm{s}^{2}\right)$ \\
\cline { 2 - 3 } 2 & SD & Dynamic identification test after first stage \\
\hline \multirow{2}{*}{$\mathbf{2}$} & DI 2 & Seismic test based on Significant Damage $-475 \mathrm{YRP}\left(\mathrm{PGA}=2.0 \mathrm{~m} / \mathrm{s}^{2}\right)$ \\
\cline { 2 - 3 } & NC & Dynamic identification test after second stage \\
\hline \multirow{2}{*}{$\mathbf{4}$} & DI 3 & Seismic test based on Near Collapse $-2475 \mathrm{YRP}\left(\mathrm{PGA}=5.0 \mathrm{~m} / \mathrm{s}^{2}\right)$ \\
\cline { 2 - 3 } & DI 4 & Dynamic identification test after third stage \\
\hline
\end{tabular}


One signal was introduced in each horizontal direction regarding the shaking table (North-South, N-S, or longitudinal and East-West, E-W, or transversal. The signals were uncorrelated, with approximately the same PGA (peak ground acceleration), PGV (peak ground velocity) and PGD (peak ground displacement) and duration of around 30 seconds in the intense phase. Before the first stage and after each stage, the model is subjected to two white-noise small amplitude inputs, specially generated with the purpose of obtaining the dynamic properties of the model (natural frequencies, mode shapes and damping ratios) and their evolution along the experimental test.

\subsection{Data Acquisition}

Several accelerometers (ACC) were attached to the structure: (i) out-of-plane behaviour of the infill walls; (ii) global behaviour of the RC concrete structure. The outof-plane behaviour of the infill walls was captured by a set of ACC distributed in the surface of the wall, see Figure 6. In model 1, due to the existence of two leaves, ACC had to be placed in the inner and outer leaves at the same position. This scheme can be seen in the outer leaf and repeats itself in the inner leaf at the exact same position, totalling thirty-eight ACC. Models 2 and 3 follow a similar scheme, which does not repeat itself in the inside since these models have single leaf infill walls. The ACC not used inside the model were applied in the outside increasing the number of measurement points considerably. The global behaviour of the RC structure was captured using two ACC orthogonally placed in the Northeast and Southwest corners of the RC slabs.

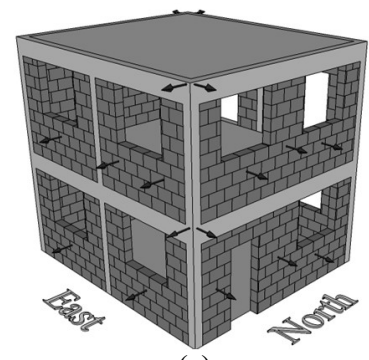

(a)

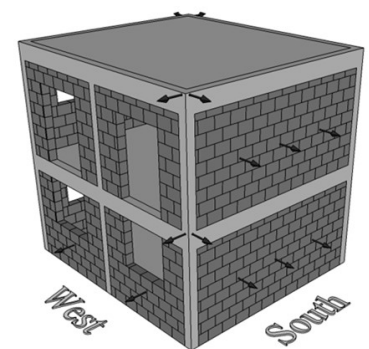

(b)

Figure 6: Accelerometers setup (Model 1): (a) North and East facades; (b) South and West facades.

\section{Shaking table test: results}

Next, the results of the shaking table tests are presented, see [11] for a full discussion. Model 1 and model 2 were subjected to the four test stages, having the first model collapsed during the last stage. Model 2 did not collapse but was heavily damaged during the last stage. Model 3 was subjected to the first three test stages but the shaking table underperformed due to technical problems and the fourth test stage was aborted. Due to the light damage presented, the model was subsequently subjected to test stages again.

\subsection{Unreinforced masonry model (Model 1)}

After the first two stages (225 and 475 YRP), model 1 did not present any visible damage, even if the dynamic data shows a small decrease in the frequencies. This loss of stiffness can be due to micro-separation of the infill walls from the RC frame or distributed micro-cracks in the RC frame or walls that remain undetected. After the third stage (2475 YRP), the model presented clear cracks on both leaves of the infill walls, see Figure 7 and Figure 8, mainly at the ground storey of the North, East and West facades. The cracks appeared mainly at the connection between the infill wall and the RC frame, and at the corners of the openings, moving towards the RC frame. In the infill walls at the ground floor in the East and West facade, and on both leaves, the crack pattern around 
several opening jambs is clear, separating them from the RC frame and the section of the infill wall below the openings. Associated with this damage, the frequencies of the first three mode shapes decreased $13.6 \%, 28.4 \%$ and $20.2 \%$, respectively, in comparison to the undamaged state.

Model 1 collapsed during the fourth stage, after expulsion of the infill walls, see Figure 9, with subsequent failure of three RC columns at the ground storey. The collapse mechanism developed, of soft storey type, was characterized by the concentration of damage at the columns. Plastic hinges should develop at the beams, dissipating the energy transferred by the earthquake without compromising stability [13]. The collapse of the columns occurred at their top, in the RC joint, followed by disintegration of the concrete and instability of the structure. This failure further stresses the need to adequately confine concrete in the joints and the need to add more stirrups to avoid shear failure. It seems that the concentration of damage and deformation of the columns in the joints was also forced by the stiff behaviour of the first storey and, possibly, the undesirable effect of the masonry infills in the ground storey, before collapse.
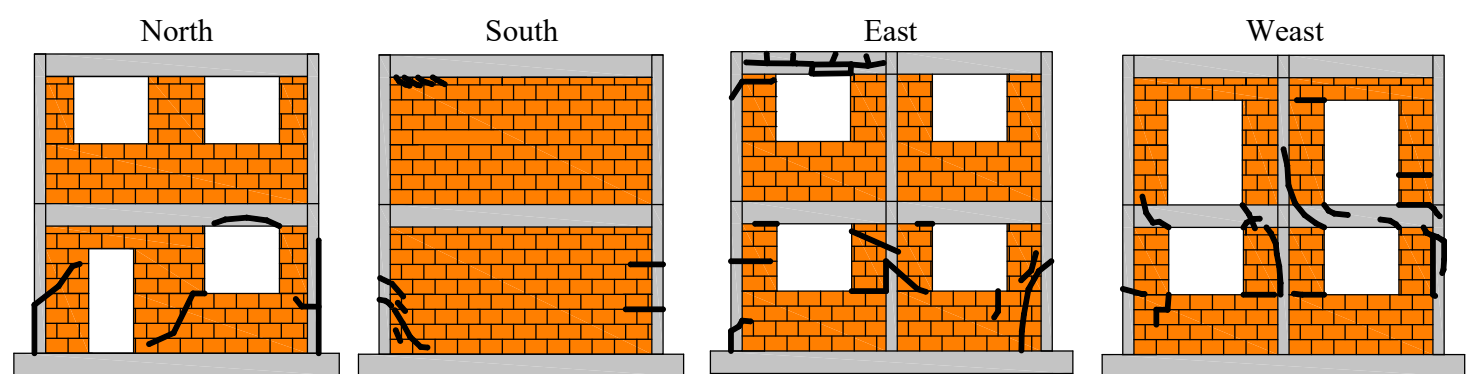

Figure 7: Crack patterns of the exterior leaf of model 1 after stage 3 (2475 YRP) (Note: the lines drawn on the $\mathrm{RC}$ frame represent damage on the clay bricks applied to the $\mathrm{RC}$ frame to avoid thermal bridges).
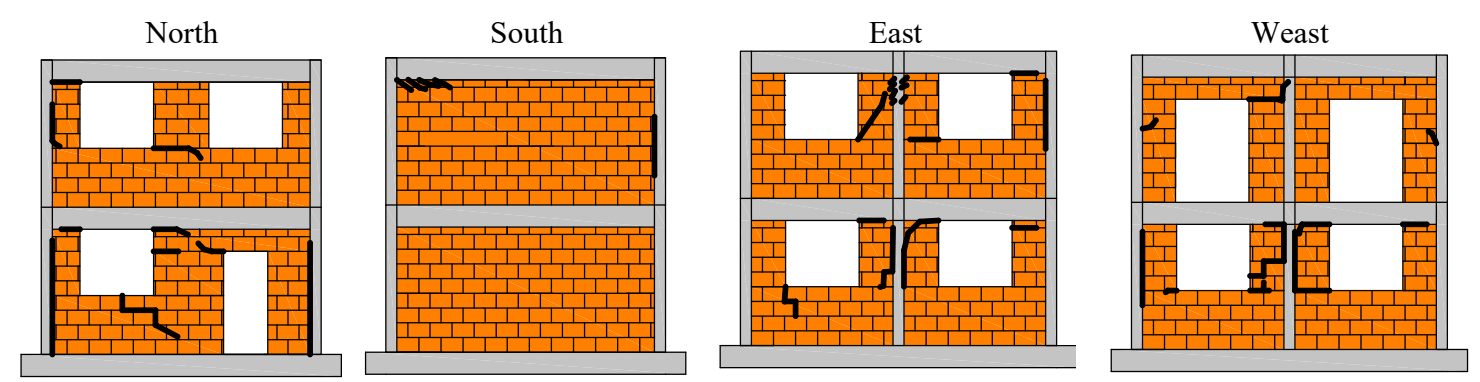

Figure 8: Crack patterns of the interior leaf of model 1 after stage 3 (2475 YRP) (Note: the lines drawn on the $\mathrm{RC}$ frame represent damage on the clay cricks applied to the RC frame to avoid thermal bridges).

Before the collapse of the RC structure, the masonry collapse occurred as is described next. First, the central jambs at the first storey of the East facade collapsed out-of-plane, see Figure 9, followed by the infill wall at the ground storey of the North facade. The exterior leaf of the infill wall at the ground floor of the South facade and the infill walls at the ground floor of the East and West facade collapsed out-of-plane simultaneously. All these infills collapsed with a rotation mechanism with a hinge line at their bottom or at the first masonry joint (as a cantilever). The interior leaf of the infill wall at the ground floor of the South facade was the last to collapse, with three hinge lines (top, centre and bottom). Immediately after, the structure collapsed. The jambs around the windows collapsed usually by rotating out-of-plane as a rigid body with a hinge line close to the connection to the spandrel (either the support or the first masonry joint), or the rest of the masonry, again as a cantilever. 


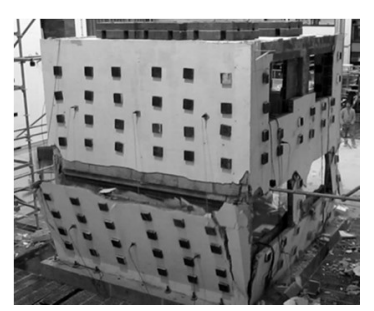

(a)
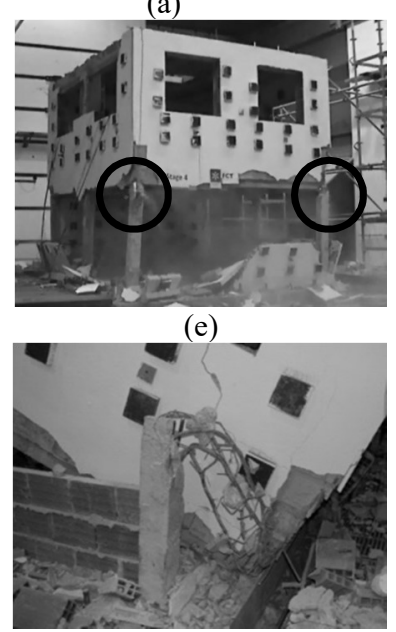

(h)

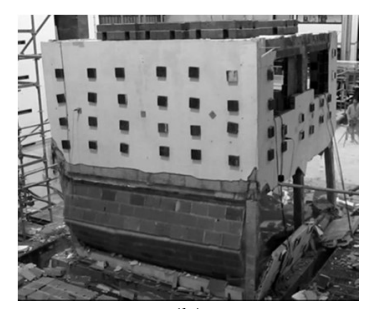

(b)

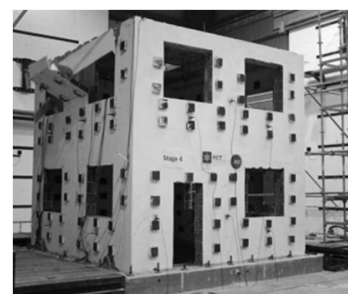

(c)

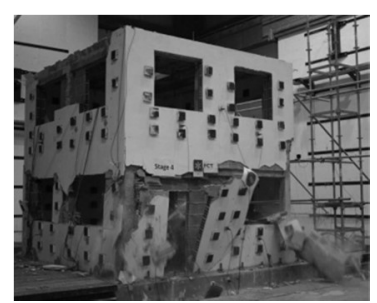

(d)
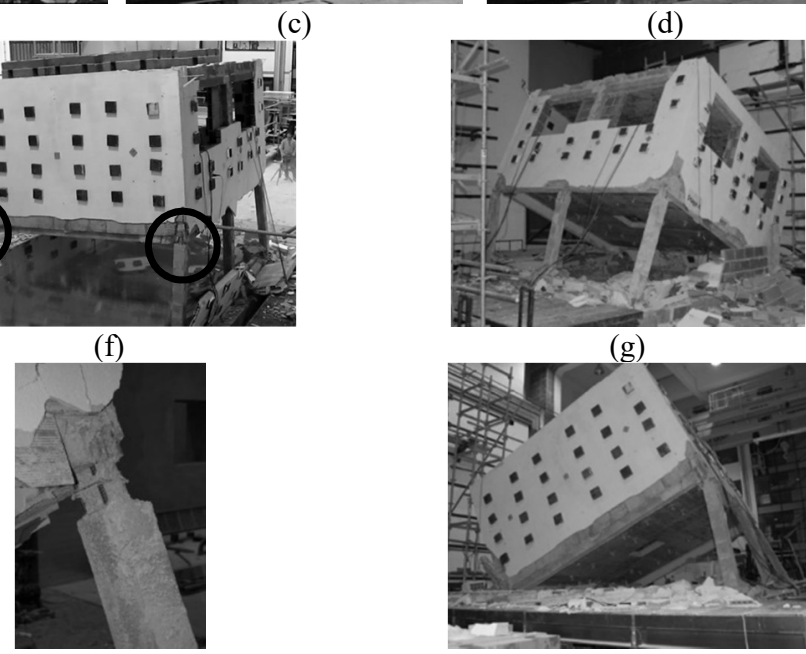

(i) (g)

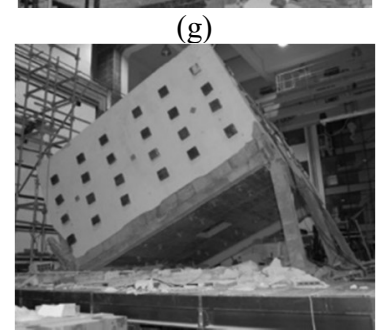

(j)

Figure 9: Stage 4 (4574 YRP) of model 1 and sequence of collapse: (a) South exterior leaf at the ground floor; (b) South interior leaf at the ground floor; (c) East exterior jambs at the first storey; (d) North leaves of the infill wall at the ground storey; (e) and (f) top of the RC columns just before full collapse; (g) Northeast view of collapse; (h) Northwest ground floor RC column with disintegration up to mid-height; (i) failure at the top Northeast ground RC column; (j) South view of collapse.

Model 1 was subjected to four dynamic identification tests, from DI 0 (undamaged state) to DI 3 (after stage 3). Five mode shapes were identified in DI 0, see Figure 10 and Figure 11, namely: the first and second transversal modes; the first and second longitudinal modes; the (first) torsional mode. As expected, the first mode is transversal (East-West) at a frequency of $7.71 \mathrm{~Hz}$, as the RC frames in that direction are single-bay and the total length of the model is smaller than in the longitudinal direction. The second mode is longitudinal (North-South) at the frequency of $9.62 \mathrm{~Hz}$ since the RC frames are double bay and the total length of the model is higher than the transversal one. Due to influence of the infill walls, and the fact that the percentage of openings is not the same in all facades, the first transversal and longitudinal modes have a very small component in the longitudinal and transversal directions, respectively.

The torsional mode has a frequency of $26.95 \mathrm{~Hz}$, considerably higher than the previous identified modes. The openings in the infills are not symmetric and it would be expected that the centre of stiffness would be closer to the Southeast corner. The mode experimentally detected presents a rotation around a point closer to the Southwest corner. Similar problems were found in the torsional modes of Models 2 and 3, and, hence, the problem can be associated to the interaction between the model and the shaking table. The fourth and fifth detected modes were, respectively, the second longitudinal at 32.84 $\mathrm{Hz}$ and the second transversal at $39.43 \mathrm{~Hz}$.

The repetition of the dynamic identification tests after each test stage, DI 1 to DI 3 , allowed detecting the decrease of the frequency of all peaks in the FRF that represent the above mentioned mode shapes (Figure 11a). Damage affects the frequency and the shape of the mode. In order to track the evolution of the mode, ensuring a correct comparison along the loading stages, the Modal Assurance Criterion (MAC) [14] was used: 


$$
M A C_{u, d}=\frac{\left|\sum_{j=1}^{m} \emptyset_{j}^{u} \emptyset_{j}^{d}\right|^{2}}{\sum_{j=1}^{m}\left(\emptyset_{j}^{u}\right)^{2} \sum_{j=1}^{m}\left(\emptyset_{j}^{d}\right)^{2}}
$$

where $\emptyset^{u}$ and $\emptyset^{d}$ are the eigenvectors for two different dynamic identification tests and $m$ is the number of degrees of freedom. The MAC was used to compare each mode shape, identified from DI 1 to DI 3, with the mode shapes identified in DI 0 and it ranges from 0 (no correlation) to 1 (perfect correlation).

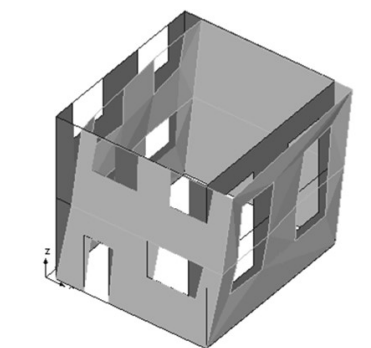

$1^{\text {st }}$ Transversal Mode $(7.71 \mathrm{~Hz})$

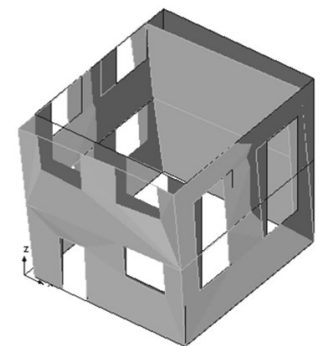

$1^{\text {st }}$ Longitudinal Mode $(9.62 \mathrm{~Hz})$

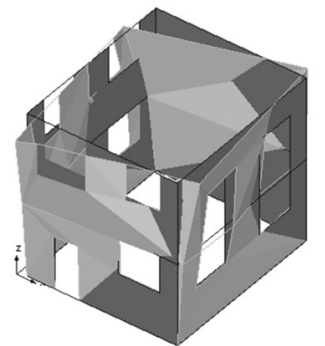

Torsional Mode $(26.95 \mathrm{~Hz})$

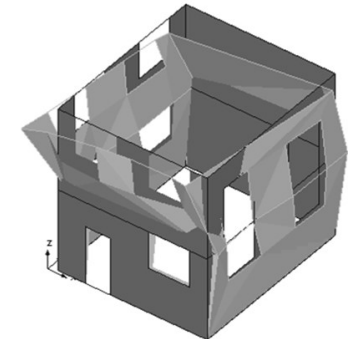

$2^{\text {nd }}$ Longitudinal Mode $(32.84 \mathrm{~Hz})$

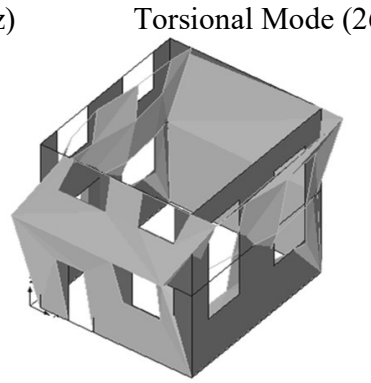

$2^{\text {nd }}$ Transversal Mode $(39.43 \mathrm{~Hz})$

Figure 10: Mode shapes of the DI 0 of model 1 (initial dynamic identification test).

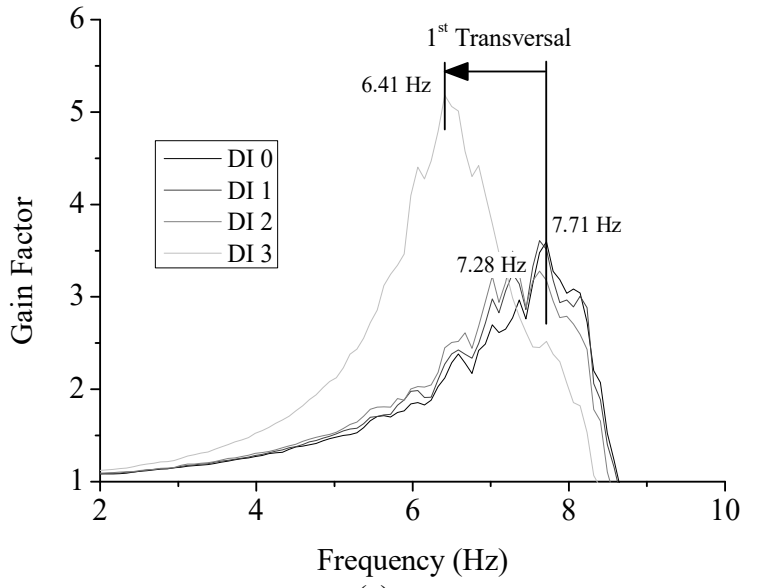

(a)

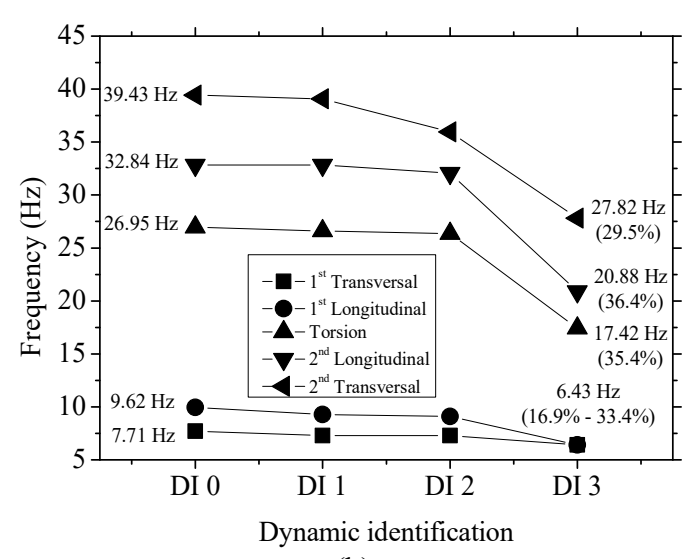

(b)

Figure 11: Frequency change along loading stages: (a) variation of the FRF's along the test of model 1 at the longitudinal accelerometer of the NE corner ( $1^{\text {st }}$ floor); (b) evolution of the frequencies along the test of model 1 and their final variation in respect to DI 0.

Figure 11 (b) presents the frequency variation of the identified mode shapes along the dynamic identifications. All five mode shapes were identified from DI 0 to DI 2, while on DI 3 the first two modes, $1^{\text {st }}$ transversal and $1^{\text {st }}$ longitudinal, merged into a single mode due to damage in the RC structure. After the first two stages of the shaking table test, all the identified mode shapes had an average frequency decrease of 3\% and the first three modes had an average MAC of 0.934 . This means that the structure was barely damaged after the 275 YRP and 475 YRP seismic actions, stages 1 and 2 respectively, and that the first three mode shapes remained unaltered. This is in agreement with the observations. 
After the third stage, the average frequency decrease of all modes was $30.3 \%$ and the average MAC of the last three modes was 0.390 . The first two modes merged into a single mode with a diagonal translation following the Southeast - Northwest direction. This severe loss of stiffness is possibly due to the separation between RC structure and infills, as the damage observed at this level is only moderate, see Figure 7 and Figure 8.

The seismic vulnerability curves presented in Figure 12 relate the damage indicator $d$ with the PGA recorded at the base of the model and the computed Input Energy for each mode shape, see also [15]. The damage indicator $d$ is computed as:

$$
d_{n}=1-f_{n} / f_{0}
$$

Equation 2

where the subscript $n$ indicates the stage and $f$ is the frequency of the given mode. This linearly proportional ratio between the $n$ stage frequency and the initial frequency (DI 0 ), varies from 0 , representing an undamaged state, to 1 , representing the collapse of the structure [16]. The damage indicator assumes isotropic damage [17] between DI 0 and stage $n$. The damage indicator of the torsional mode was associated to the direction with the highest recorded PGA and Input Energy (longitudinal direction in case of model 1).

The damage indicator is in agreement with the observed damaged, with a very low value after the first two stages (225 and 475 YRP) and a considerable leap after the third stage ( 2475 YRP). With the exception of the $1^{\text {st }}$ transversal mode, all other modes have a damage indicator between 0.30 and 0.36 after the third stage, confirming a generalized loss of stiffness of the structure and the evenly distributed damage along the four facades of the structure that was observed. The damage indicator reached the unitary value for the maximum recorded PGA at stage 4 (4574 YRP). Note also that in Figure 12 there is a strong jump in the PGA and Input Energy in the last stage. This is due to the fact the input in shaking tables depend on the dynamics of the structure itself and, in case of severe damage or collapse, the response cannot be fully controlled.
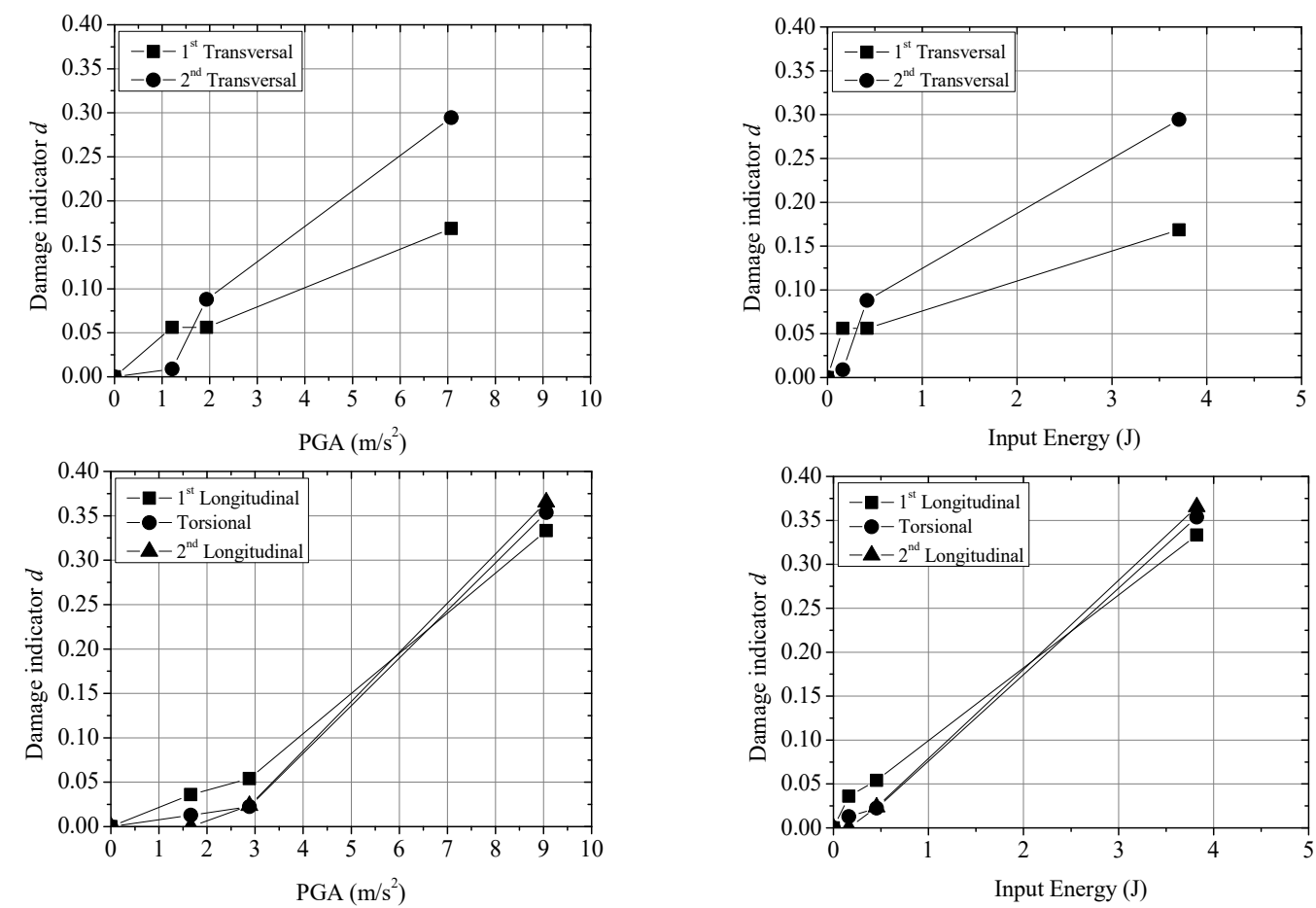

Figure 12: Seismic vulnerability curves of model 1 in the transversal and longitudinal directions, using the PGA and the Input Energy as input. Here, the damage is estimated through the frequency change. 
The frequencies of the infill walls were also monitored, see Figure 13. Only the first mode shape of the North and South walls were identified. The results showed that the exterior leaves have a slightly higher frequency when compared to interior ones, which is expected because the stiffness increases to the third power of the thickness while the mass only increases linearly. The reason for the small increase is likely to be the boundary conditions, as the exterior leaves are partly overhanging the slab, thus with lower restriction to rotation. The infills of the South facade have a higher frequency than the infills at the North facade, in the same position, due to the lack of openings.

After the first test stage, DI 1, the infill walls did not present any considerable frequency decrease. After the second stage, in which no damaged was observed and no considerable frequency decrease was registered in the global structure, the infill walls of the ground floor of the south facade and the exterior leaf of the ground floor of the North facade presented a frequency decrease of $16.4 \%, 7.7 \%$ and $4.2 \%$, respectively. This frequency loss, since the walls did not present any visible damage, is likely to be due to the small loss of connection between the infill and RC frame.

After stage 3, the infill walls of the South facade had an average frequency loss of $16.4 \%$ while the walls on the North facade had an average frequency loss of $15.0 \%$. In the South facade, the exterior and interior leaves, both in the ground and first floors, converged to the same frequency after in DI 3, which indicates larger damage in the exterior walls. The same situation was not registered in the North facade, where stiffness reduction was proportional, with the exception of the P1 external leaf. The infill walls of the ground floor presented a higher frequency loss when compared to the ones on the first floor, which is in agreement with the observed damage. The exterior leaf of the infill wall of the ground floor at the North facade presented a frequency loss of $43.1 \%$, which is in agreement with the observed damaged since this infill was more damaged than any other in the transversal direction, and it was one of the first walls to completely collapse outof-plane.

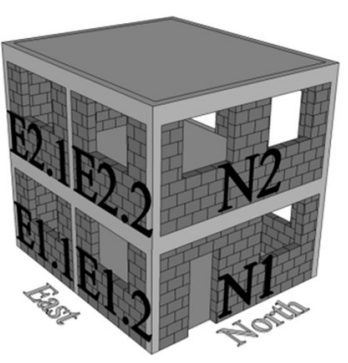

North facade infill walls

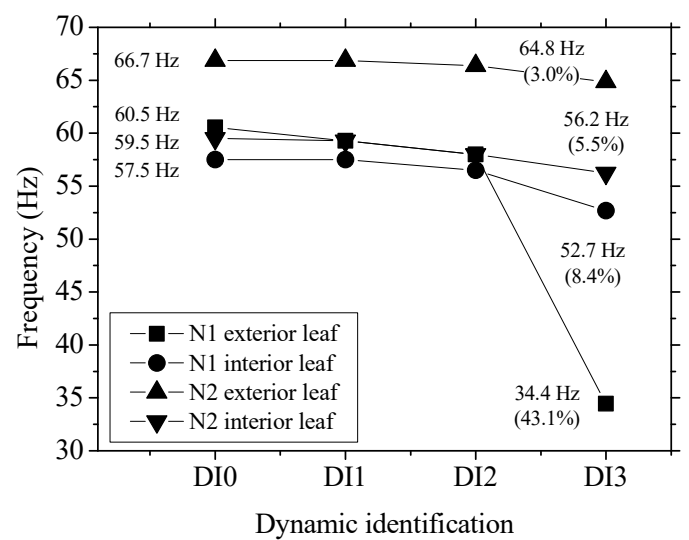

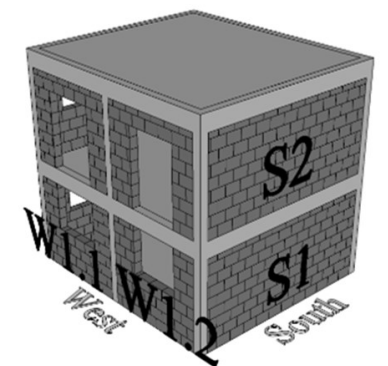

South facade infill walls

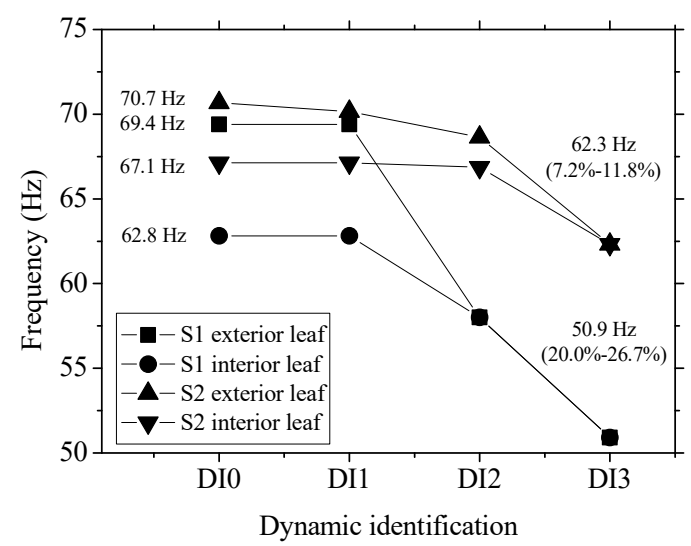

Figure 13: Evolution of the frequencies of the infill walls in the North and South facades along the test of model 1 and their final variation in respect to DI 0 . 


\subsection{Reinforced masonry models (Model 2 and Model 3)}

After the first two stages (225 and 475 YRP), model 2 (with bed joint reinforcement) did not present any visible damage and presented negligible frequency decrease. After stage 3 (2475 YRP), the model presented the crack pattern shown in Figure 14, with all damage concentrated at the ground floor. The concentration of lines around the RC columns represents mortar rendering expulsion, leaving nearly half of the $\mathrm{RC}$ column visible, although no cracks were visible in the $\mathrm{RC}$ elements. Cracks starting from the corners of the openings and progressing towards the $\mathrm{RC}$ frame were also visible after stage 3 in most of the openings. In the East and West facade, the crack pattern around several jambs is clear, separating them from the RC frame and the section of the infill wall below the opening, just as in model 1 but not as clear. The inside face of the model also presented expulsion of the rendering at the intermediate columns of the East and West facades, leaving the RC columns visible, and a crack pattern similar to the outside one. Model 2, contrary to model 1, did not collapse during the fourth and last stage of the test (4574 YRP), but it was heavily damaged.
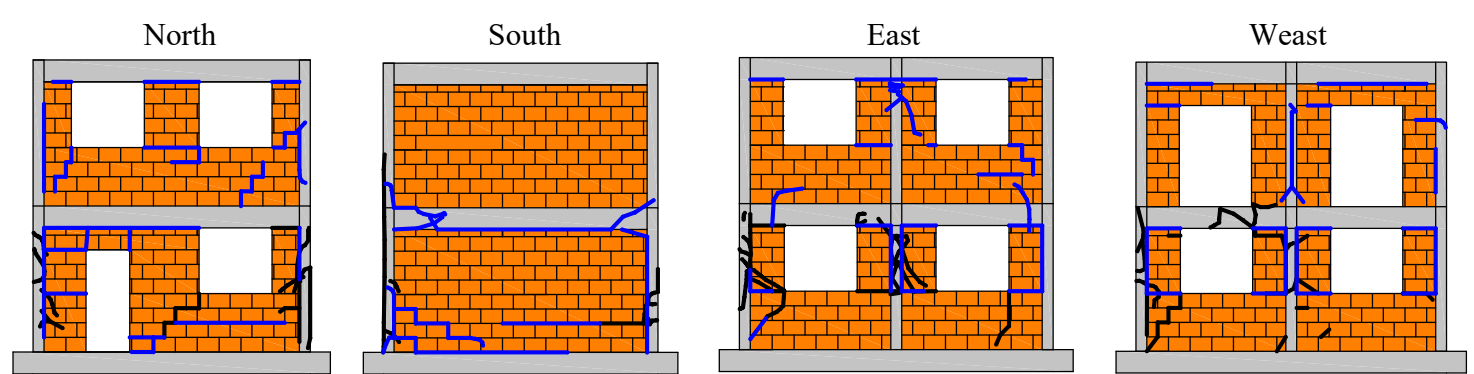

Figure 14: Crack patterns of model 2 after stage 4 (4574 YRP) (Notes: the drawn lines on the RC frame represent damage on the rendering applied to the RC frame. The blue lines developed after stage 3).

The modes were the same as in model 1 . Figure 15 presents the frequency variation of the model along the test. After the first two stages (225 and 475 YRP) the model did not present a frequency decrease, which is in agreement with the observed damage results. During stage 3 (2475 YRP) the model endured considerable damage in the RC structure, with an average frequency loss of $13.0 \%$ in the transversal direction (first and second modes) and $38.2 \%$ in the longitudinal direction (first and second modes). The first transversal and longitudinal modes switched positions and the torsional mode also had a frequency decrease of $36.7 \%$. The last stage (4574 YRP) left the model near collapse and the first transversal and the first longitudinal modes merged, with an average loss of frequency of $78 \%$, with the new mode being a torsion with the centre of rotation very close to the South face, therefore with a high amplitude motion of the North facade.

The seismic vulnerability curves presented in Figure 16 confirm the observed damage and dynamic data, as until stage 2 (475 YRP) none of the mode shapes present significant damage and after stage 3 (2475 YRP) the longitudinal modes presented an average damage of 0.38 while the transversal modes present an average damage of 0.14 . After stage four (4574 YRP), the first and second mode presented a damage around 0.8, indicating the already mentioned near collapse state. 


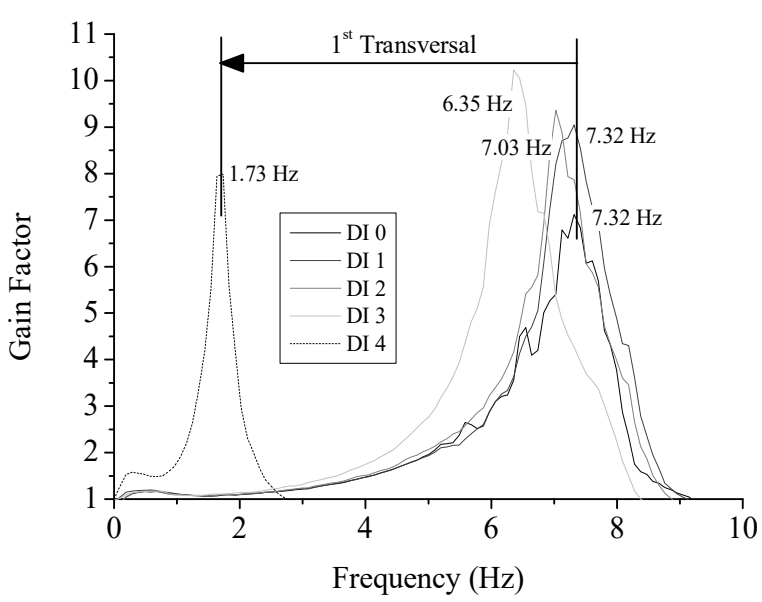

(a)

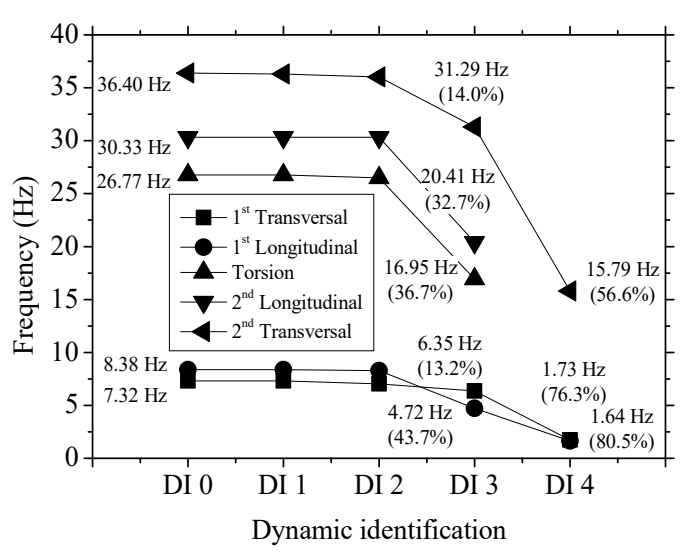

(b)

Figure 15: Frequency change along loading stages: (a) variation of the FRF's along the test of model 2 at the transversal accelerometer of the NE corner ( $2^{\text {nd }}$ floor); (b) evolution of the frequencies along the test of model 2 and their final variation in respect to DI 0.
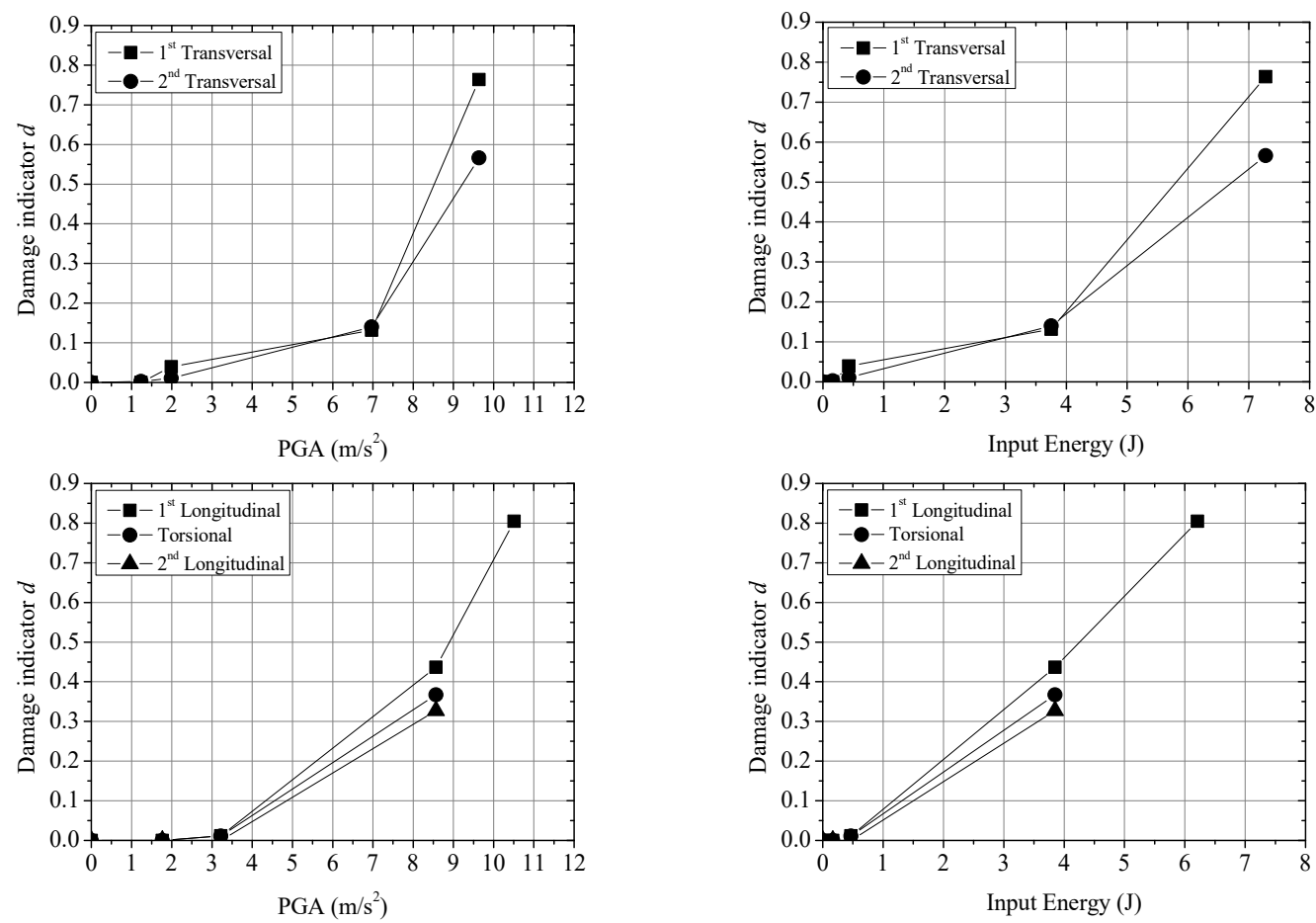

Figure 16: Seismic vulnerability curves of model 2 in the transversal and longitudinal directions, using the PGA and Input Energy as input.

Figure 17 presents the frequency decrease of the infill walls on the South facade and at the ground floor of the North facade. As expected, the infills of the South facade present a higher frequency as they have no openings. The infill walls present an initial small frequency decrease, after stage 2 (475 YRP), even without any visible damage, possibly associated to some loss of connection between the infill wall and the RC frame. After stage 3 (2475 YRP), the infill walls at the ground floor presented a frequency decrease of around $20 \%$, while the infill at the upper floor presented a decrease of $12 \%$. After the last stage (4574 YRP) the infill wall at the ground floor of the North facade was so damaged and detached from the RC frame that it was not possible to identify its first modal frequency. 


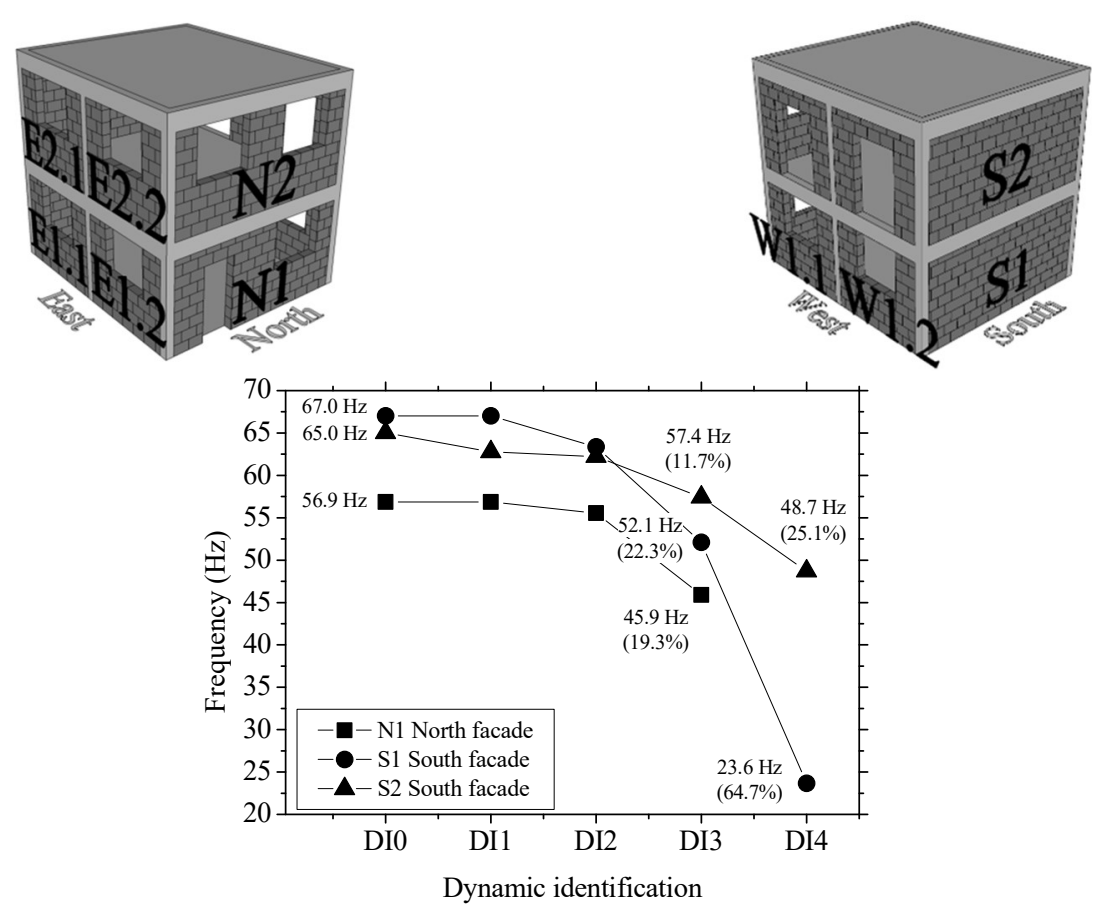

Figure 17: Evolution of the frequencies of the infill walls in the North and South facades along the test of model 2 and their final variation in respect to DI 0.

After stage 2 (475 YRP), model 3 (with reinforced plaster) presented cracks in the mortar rendering in all four corners, starting at the base of the RC column, and between the jambs on the intermediate columns of the East and West facades, see Figure 18. Small cracks starting at the corners of some of the openings and moving towards the $\mathrm{RC}$ frame were also visible at the ground floor, while the first floor presented no visual damage. After stage 3 (2475 YRP), the cracks in the mortar at the corners of the models extended and small pieces of mortar rendering fell. The cracks in the jambs of the East and West facade also were further extended. New cracks surrounding the ground floor infills of the North and South facades appeared, along with some cracks in the infill wall at the first storey of the North facade, mainly between the openings. Overall, the model presented light damage, and the cracks seemed to affect only the mortar.
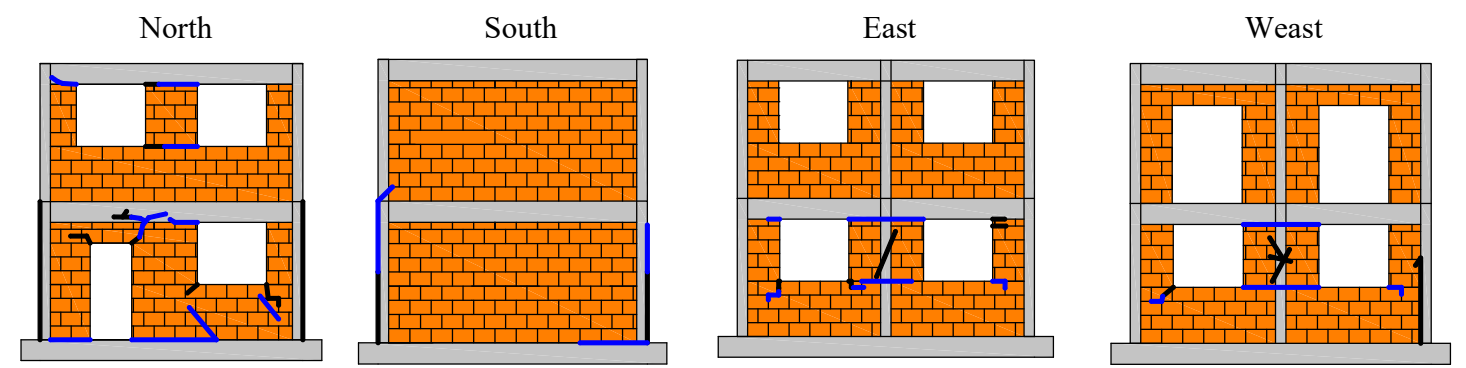

Figure 18: Crack patterns of model 3 after stage 3 (2475 YRP) (Notes: the drawn lines on the RC frame represent damage on the rendering applied to the $\mathrm{RC}$ frame. The blue lines developed after stage 3 ).

The dynamic identifications provided the five mode shapes as in the previous models, although the first transversal and first longitudinal changed positions, which is most likely associated to the interaction between the model and the shaking table and /or the interaction between masonry infill and frame, which depends on workmanship and the actual execution of each infill. Until the second stage, the longitudinal direction presented no frequency decrease, the transversal direction presented an average $5.1 \%$ frequency decrease and the torsional mode presented a 5.5\% frequency decrease, see Figure 19. 
After stage 3 (2475 YRP), the average decrease in the longitudinal direction was $15.6 \%$ and the average frequency loss in the transversal direction was $24.0 \%$. The torsional mode presented a $31.1 \%$ decrease.

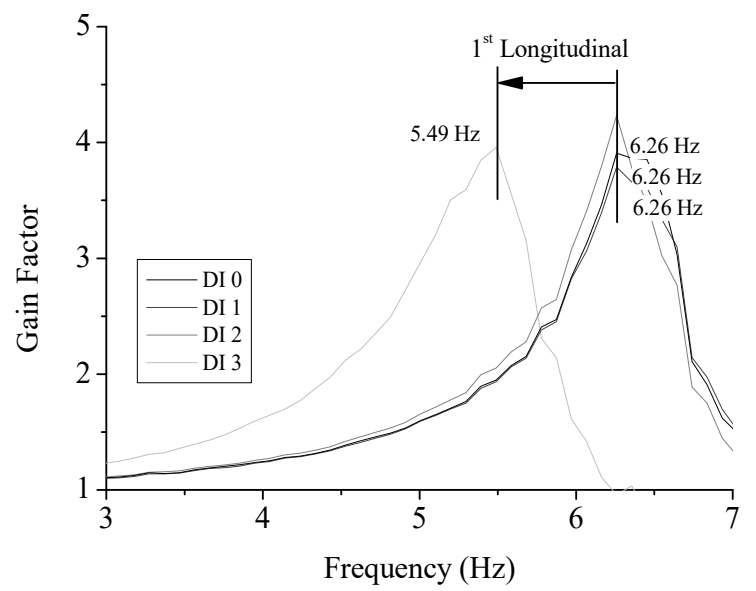

(a)

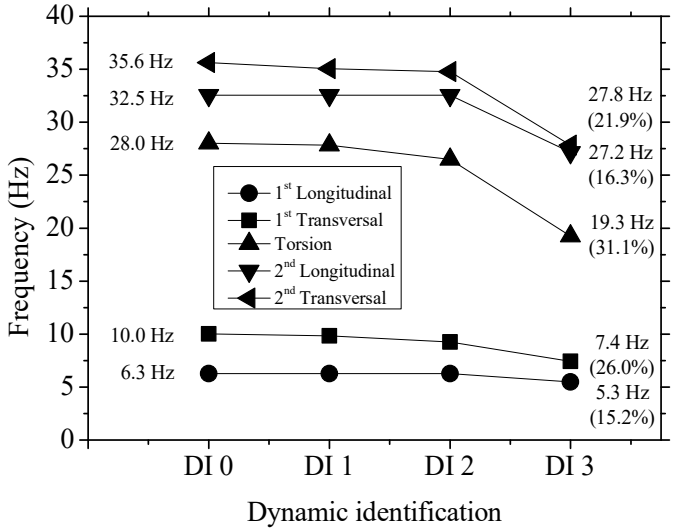

(b)

Figure 19: Frequency change along loading stages: (a) variation of the FRF's along the test of model 3 at longitudinal accelerometer of the NE corner ( $1^{\text {st }}$ floor); (b) evolution of the frequencies along the test of model 3 and their final variation in respect to DI 0.

The vulnerability curves confirm that the longitudinal direction presented no considerable damage until the second stage. After stage 3 (2475 YRP), the transversal direction presented considerably more damage when compared to the longitudinal one, which can be associated to the different Energy Input. The damaged indicator reached a maximum of 0.3 , far lower than the other models, tested up to stage 4 .

Therefore, a new sequence of tests was carried out with this model, increasing the input again according to the desired spectra. After three new test stages, the model still did not present much damage as no new cracks appeared but the ones at the corners widened considerably and parts of mortar rendering were expelled. The reinforced rendering became loose, as if it was completely disconnected from the infill walls. This confirms the importance of the connections of reinforced plaster to the walls, which should cross the entire thickness of the wall. The upper level presented no significant damage with only small cracks at the corners of the openings. This condition was assumed as an ultimate condition, given the frequency decrease and the fact that no damage of the structure was desired. The loose reinforced rendering was removed as a whole on both sides of the infill walls. Careful analysis of the un-plastered infill walls showed that these presented limited damage, but were disconnected from the RC frame. Hence, the reinforced plaster was preventing the out-of-plane collapse of the infill walls. As for the $\mathrm{RC}$ structure, no cracks were detected at mid-height of the RC columns, but only at the upper connection to the beams. The $\mathrm{RC}$ was very flexible under these conditions, meaning that the reinforced plaster increased the robustness of the structure and was preventing the collapse of the entire system.

Figure 20 presents the frequency decrease of the RC structure and of three infill walls in the model along the three additional test stages. The initial dynamic identification, DI 0 , corresponds to end of the first test stage. In the RC structure, the identification of the (first) torsional and second longitudinal and transversal modes was not possible after stage 3 (2475 YRP). The first transversal mode presented a higher stiffness loss when compared to the longitudinal mode. After stage 2 (475 YRP) the modes presented $0.2 \mathrm{~Hz}$ of difference between them and after stage 3 the transversal direction presented a higher 
stiffness loss. At the end of the test, the transversal direction presented a $73.5 \%$ frequency loss, while the longitudinal direction presented a $48.6 \%$ decrease, when compared to the undamaged state. This difference can be associated to the infill walls at the ground floor, which on the transversal direction presented a clear disconnection to the $\mathrm{RC}$ frame at the jambs.

The infill wall at the upper level of the South facade presented an extra $12.2 \%$ of frequency decrease during the three stages, which add to the previous damage totalizing $19.8 \%$, when compared to the undamaged state. This infill wall did not present any visible damage, and the loss of stiffness is associated to the loss of connection between the infill wall and the RC frame. The infill walls at the ground floor presented a similar and considerably higher frequency loss at the end of stage 3 , when compared to the upper level one, although the South infill wall presented the highest loss at the first stage (225 YRP) and the North one presented the highest loss in the last stage.
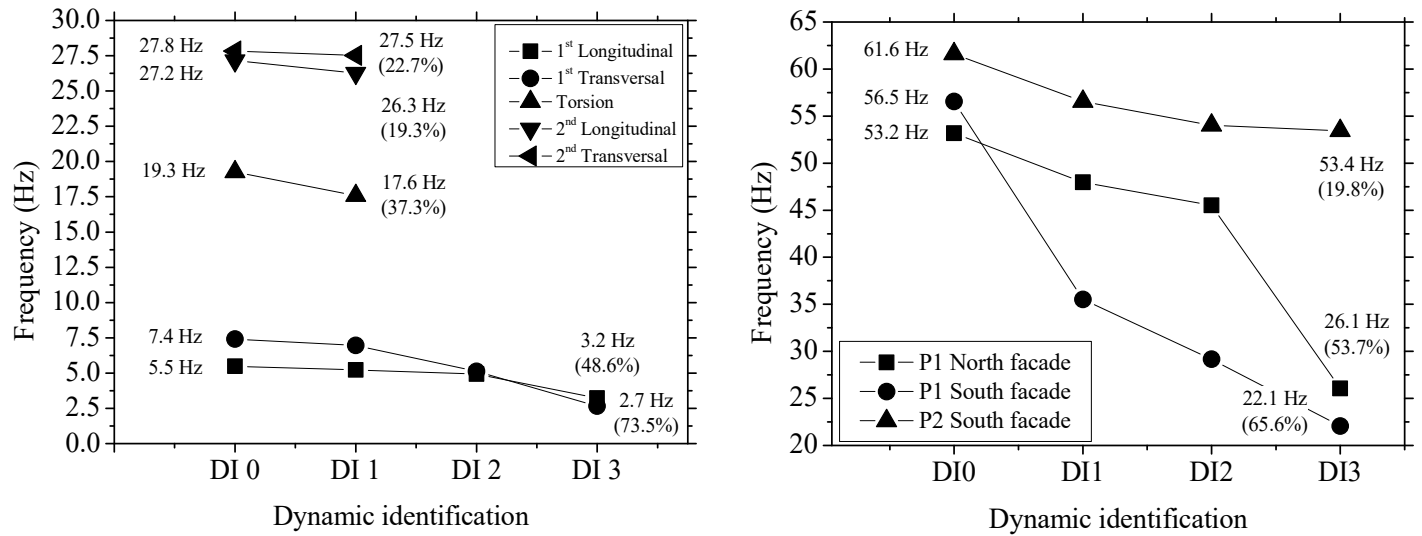

Figure 20: Evolution of the frequencies along the test of model 3 with additional stages, and their final variation in respect to DI 0, at the RC structure and infill walls in South facade and ground level of the North facade.

\subsection{Hysteretic curves}

The response of the models in terms of hysteretic behaviour was also evaluated. Since the response corresponds to non-linear dynamic behaviour obtained from shaking table tests and aiming at providing an easy interpretation of the results, only the envelopes of the hysteric behaviour were plotted. The envelopes represent the maximum and minimum response of the models for the relationship between the load factor (ratio between the inertial forces and the self-weight) and the interstory drift. Furthermore, in the last stage of the shaking table tests the models presented severe damage or collapsed, causing very high displacements. Thus, only the envelopes of the first three stages are presented.

Figure 21 presents the envelopes of the hysteric behaviour of the model 1 (unreinforced model) for each floor in the longitudinal and transversal direction. The maximum load factor in the longitudinal direction is equal to $0.16,0.28$ and 0.76 for stage 1 , stage 2 and stage 3, respectively. In transversal direction the maximum load factor is equal to $0.15,0.25$ and 0.63 for stage 1 , stage 2 and stage 3 , respectively. 


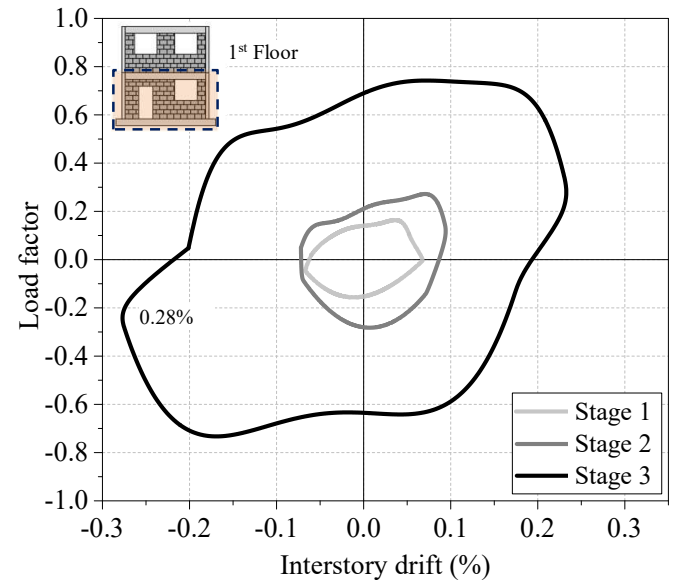

(a)

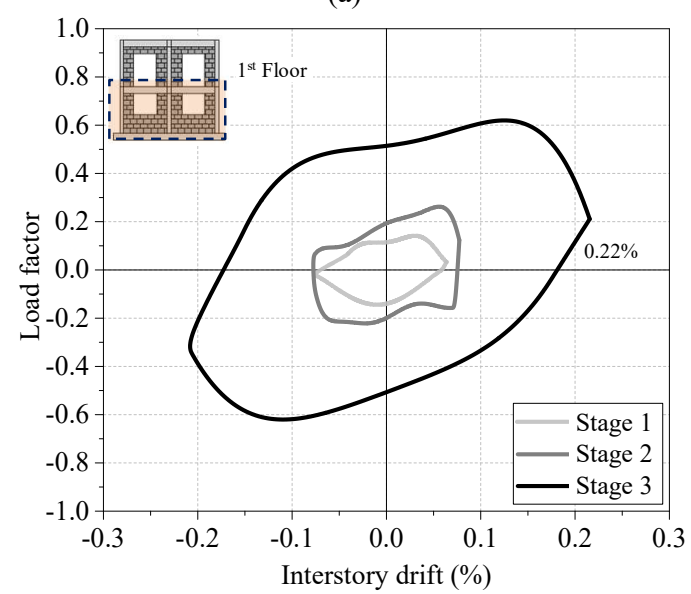

(c)

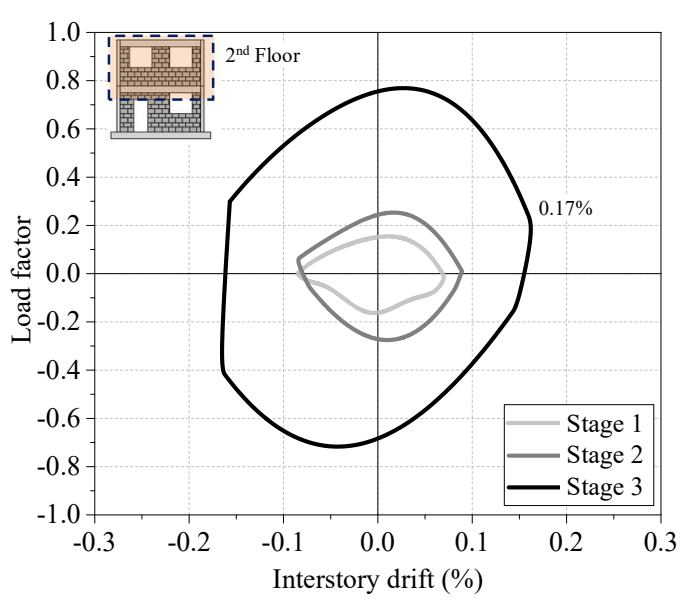

(b)

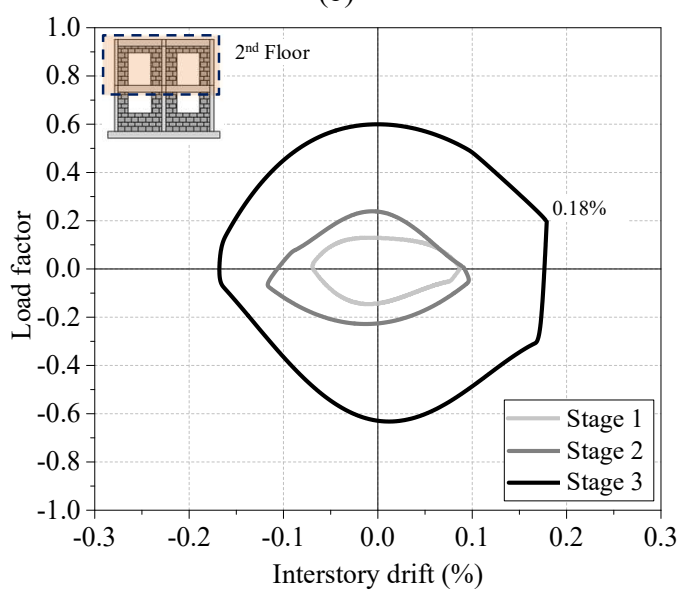

(d)

Figure 21: Envelopes of the hysteric behaviour for model 1 (39.5 ton): (a) load factor in the longitudinal direction vs. interstory drift of $1^{\text {st }}$ floor; (b) load factor in the longitudinal direction vs. interstory drift of $2^{\text {nd }}$ floor; (c) load factor in the transversal direction vs. interstory drift of $1^{\text {st }}$ floor; (d) load factor in the transversal direction vs. interstory drift of $2^{\text {nd }}$ floor.

The maximum interstory drift of the model 1 occurs at the first floor and is equal to $028 \%$ and $0.22 \%$ in the longitudinal and transversal direction (stage 3), respectively, which is according to the concentration of damage at the first floor observed in the shaking table tests. The interstory drift at the first floor presents a significant variation between the stage 2 and the stage 3 (about 65\%), showing that in stage 3 model 1 presented significant damage. This aspect is in agreement with the variation of frequencies, in which a decrease of about $30.3 \%$ for all modes was observed after stage 3 . It is noted that model 1 collapsed during stage 4 .

Model 2 (with bed joint reinforcement) presents similar maximum load factors for both directions (Figure 22). However, this model presents a maximum load factor (0.62) lower than the maximum load factor of model $1(0.76)$ for stage $3(-20 \%)$. The maximum interstory drifts occurs at the first floor, namely $0.37 \%$ in the longitudinal direction and $0.27 \%$ in the transversal direction, showing that the damage concentrates at the first floor. Model 2 presents a more flexible dynamic response when compared to the response of model 1, which is in agreement with the stiffness and frequencies of the models. In stage 3 , model 2 presents an interstory drift for the first floor higher than model 1 with a damage with lower severity. These aspects lead to the conclusion that the model 2 presents higher ductility than model 1, allowing more dissipation of energy and improving the dynamic behaviour of the structure, which is in agreement with the fact that the RC structure of 
model 1 was designed using the older Portuguese standards [4] [5] while the RC structure of model 2 was designed using Eurocodes 2 [6] and 8 [7]. It is noted that model 2 was heavily damaged, but did not collapse (even for stage 4).

Model 3 (reinforced plaster) was subjected to the first three stages. Due to the light damage presented by this model, the first three stages were repeated. During the first three stages model 3 presented a maximum load factor equal to 1.11 and 1.25 in the longitudinal direction and transversal direction, respectively (Figure 23). The maximum interstory drift in the transversal direction occurs at the first floor and is equal to $0.31 \%$ (stage 3 ). However, and contrarily to what was observed in the other models, the interstory drift of the second floor is slightly higher than the drift of the ground floor for all the stages. Although the interstory drifts of model 3 are higher than the interstory drifts of model 1 (unreinforced model) for stage 3 , this model did not present severe damage.

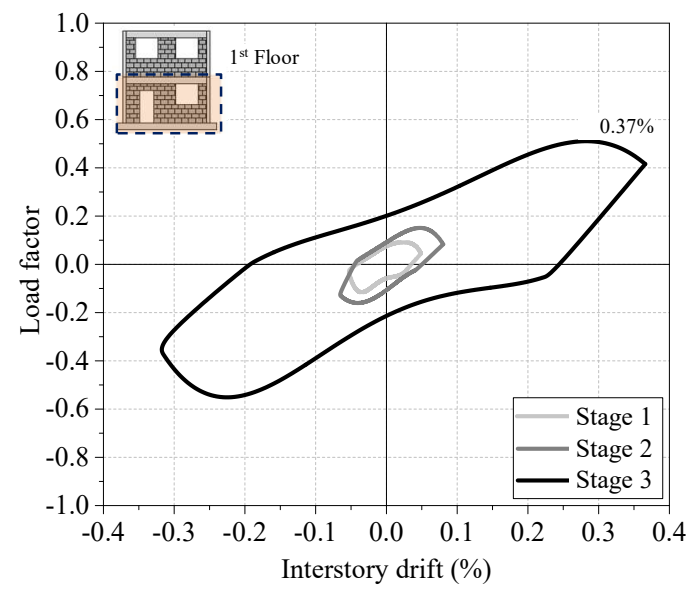

(a)

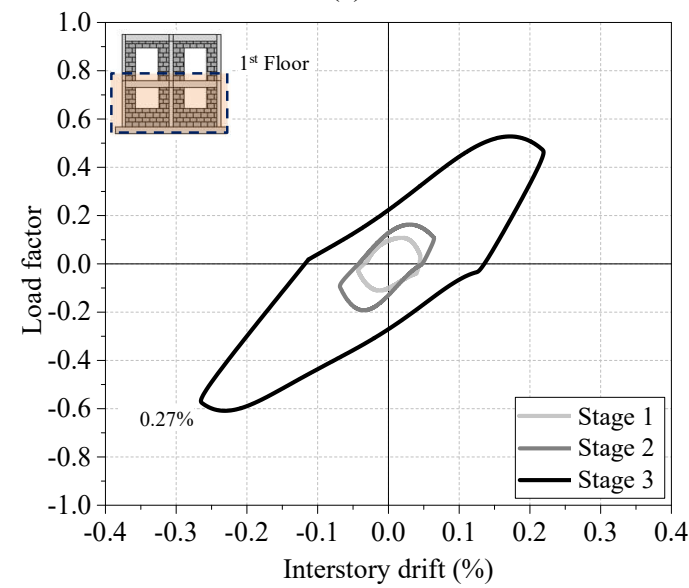

(c)

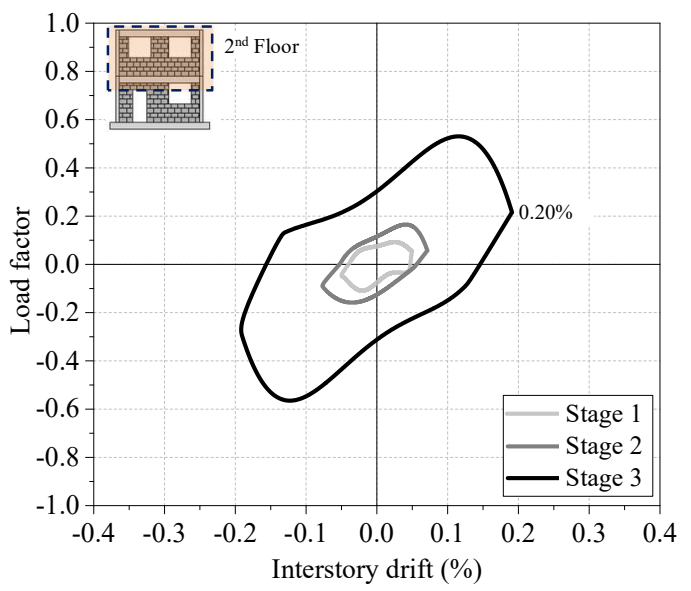

(b)

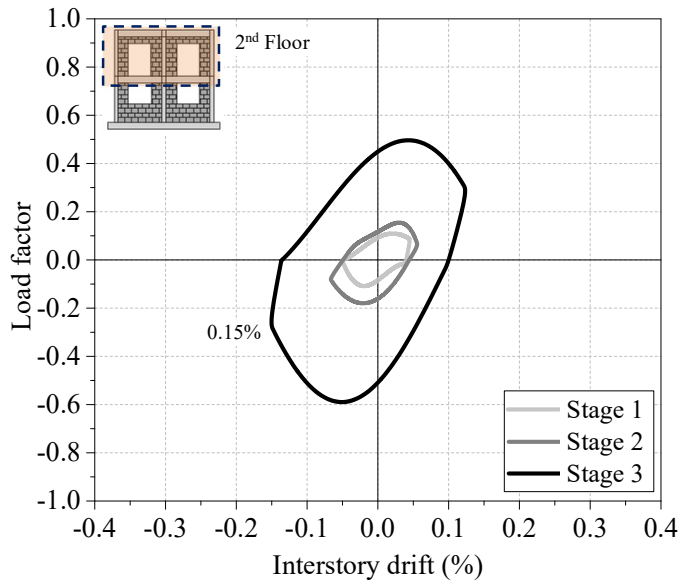

(d)

Figure 22: Envelopes of the hysteric behaviour for model 2 (37.7 ton): (a) load factor in the longitudinal direction vs. interstory drift of 1 st floor; (b) load factor in the longitudinal direction vs. interstory drift of 2nd floor; (c) load factor in the transversal direction vs. interstory drift of 1st floor; (d) load factor in the transversal direction vs. interstory drift of 2 nd floor.

In the subsequent three stages to which model 3 was subjected, a more flexible response was recorded, which is due to the accumulative damage and is in agreement with the expected response (Figure 23). In the second stage 3 (Stage3_2) the maximum factor in the longitudinal and transversal directions is equal to 0.87 and 0.96 , respectively. The maximum load factors present a decrease of about $22 \%$ with respect to the first stage 3 , showing that due to the previous damage the model does not present the same capacity 
force. As a consequence, the interstory drifts increased significantly. The final maximum interstory drift is equal to $1.05 \%$ and $1.33 \%$ in the longitudinal and transversal direction, respectively. It is noted that even for these drift values, model 3 did not collapse. Once again, the interstory drift in the longitudinal direction of the second floor is higher than the interstory drift of the first floor in the repetition of the two first stages. Only the in last stage (Stage3 2) was the interstory drift in the longitudinal direction of the first floor higher than the interstory drift of the second floor. This aspect shows that model 3 presents a significant improvement in the response of the first floor in the most flexible direction of the structure (longitudinal). It is noted that, contrarily to the other models and according to the frequencies of the modes, the most flexible direction of the model corresponds to the longitudinal direction. Based on the hysteric behaviour, it is concluded that the reinforcement technique adopted in model 3 is able to improve significantly the seismic performance of the structure, mainly in the most flexible direction.

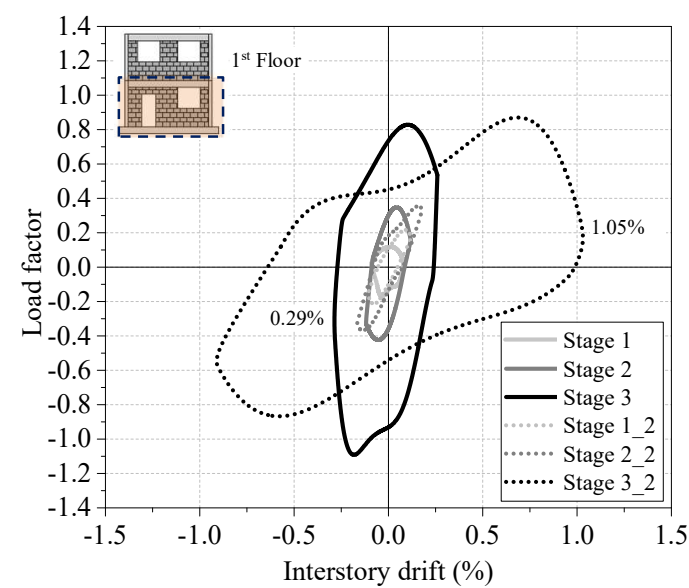

(a)

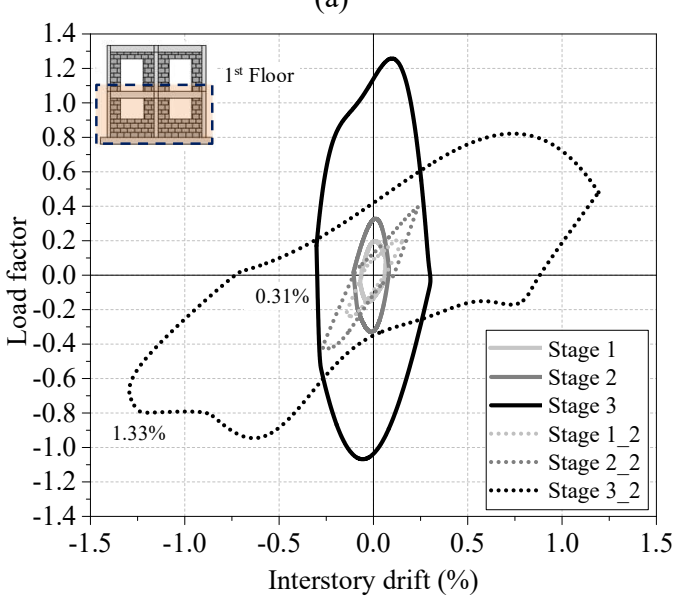

(c)

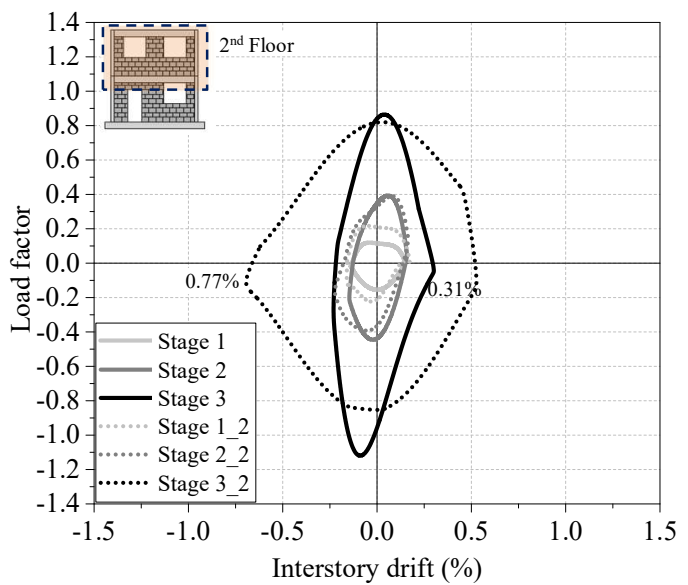

(b)

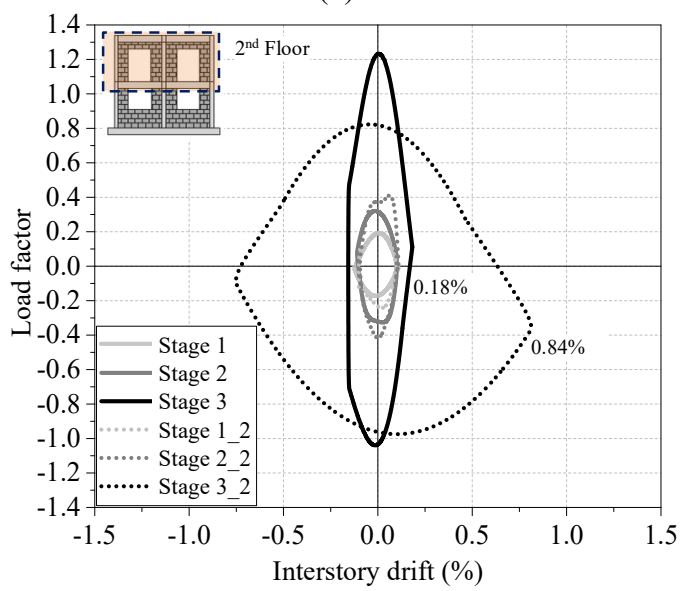

(d)

Figure 23: Envelopes of the hysteric behaviour for model 3 (37.7 ton): (a) load factor in the longitudinal direction vs. interstory drift of $1^{\text {st }}$ floor; (b) load factor in the longitudinal direction vs. interstory drift of $2^{\text {nd }}$ floor; (c) load factor in the transversal direction vs. interstory drift of $1^{\text {st }}$ floor; (d) load factor in the transversal direction vs. interstory drift of $2^{\text {nd }}$ floor.

\section{Conclusions}

This paper presents the results of shaking table tests on three reinforced concrete frames with masonry infills. Model 1 includes a double leaf wall, unreinforced, which is typical of the construction in Portugal in the last 40 years, while models 2 and 3 adopt a single thicker infill with bed joint reinforcement and reinforced plaster, which is believed 
to constitute the next generation of infills. The RC frames were designed according to the applicable regulation at the time for a 475 YRP seismic design response spectrum and a ground of rock or other rock-like geological formation, including at most $5 \mathrm{~m}$ of weaker material at the surface.

All models exhibited excellent performance for the design response spectrum, with no visible damage and very small stiffness loss. This behaviour was due to the masonry infills, which, given the asymmetric disposition of openings, also introduced a strong torsion in the models. With respect to collapse, model 1 collapsed for a 4574 YRP, while the other models did not albeit they seemed very close to it.

Model 1 exhibited a soft storey collapse mechanism after expulsion of the ground floor infills, with damage in the RC columns at mid-height and top before the collapse of the structure. Some of the masonry elements applied to avoid thermal bridges at the concrete elements, a very common solution in the Portuguese built heritage, cracked and fell during stage the 2475 YRP earthquake. The double leaf unreinforced infill collapsed out-of-plane by rotating as a rigid body around the bottom of the wall. The interior and exterior leaves presented a similar seismic behaviour.

Model 2 did not collapse during the 4574 YRP earthquake but presented severe damage and the RC structure also developed a soft storey mechanism. The mortar rendering applied to the RC frame was severely damaged after the 2475 YRP earthquake, especially at the corners of the model. The single leaf infill walls with bed joint reinforcement did not collapse out-of-plane in the last stage because it was connected to the $\mathrm{RC}$ frame, otherwise it is expected that the infill walls would have collapsed as a rigid body.

Model 3 presented the least damage for the 2475 YRP earthquake. After the reinforced rendering removal, the $\mathrm{RC}$ columns presented neither hinges at the extremities nor cracks at mid-height; hence no undesirable collapse mechanism was developed. The infill walls presented light damage after all the stages, even though the dynamic data presented a clear stiffness loss. This was due to detachment of the infill wall from the reinforced rendering, allowing the wall to move. The reinforced rendering prevented the out-of-plane collapse; furthermore, it is recommended to connect both sides of the rendering with connectors to prevent the collapse.

\section{References}

1. Mehrabi, A.B., Shing, P.B., Schuller, M.P. and Noland, J.L. (1994). Performance of Masonry-Infilled R/C Frames Under In-Plane Lateral Loads. Report No. CU/SR-94-6, University of Colorado, Boulder.

2. El-Dakhakhni, W., Elgaaly, M. and Hamid, A. (2003). Three-Strut Model for Concrete Masonry-Infilled Steel Frames. J. Struct. Eng., 129(2), 177-185.

3. Tiedemann, H., A statistical evaluation of the importance of non-structural damage to buildings, Proccedings 7th WCEE, Istanbul, 1980, Vol. 6, pp.617-624.

4. REBAP (1983). Code for reinforced and presstressed concrete structures. Diário da República. (in Portuguese)

5. RSA (1983). Code for safety and actions for building and bridge structures. Diário da República. (in Portuguese)

6. Eurocode 2 (2002). Eurocode 2: Design of concrete structures - Part 1: General rules and rules for buildings, (EN-1992-1-1) European Committee of Standardization. Brussels, Belgium. 
7. Eurocode $8(2004,2005)$. Design of structures for earthquake resistance - Part 1: General rules, seismic actions and rules for buildings (EN 1998-1). Part 3: Assessment and retrofiting of buildings (EN 1998-3), European Committee of Standardization Brussels, Belgium.

8. Carvalho, E. C. (1998). Seismic testing of structures. 11th European Conference on Earthquake Engineering. Balkema, Rotterdam.

9. Bedell, R. J. and D. P. Abrams (1983). Scale relationships of concrete columns. University of Colorado.

10. Pereira, M. F. P. (2013). Avaliação do desempenho das envolventes dos edifícios face à acção dos sismos (in Portuguese). Department of Civil Engineering, University of Minho. $\mathrm{PhD}$ thesis. http://hdl.handle.net/1822/25612

11. Leite, J.M. (2014). Seismic behaviour of masonry infill walls: test and design. Department of Civil Engineering, University of Minho. $\mathrm{PhD}$ thesis.

12. Mendes, L. (2008). LNEC-SPA: Signal Processing and Analysis Tools for Civil Engineers. Earthquake Engineering and Structural Dynamics Division, National Laboratory for Civil Engineering, Lisbon, Portugal.

13. Baker, J. and J. Heyman (1969). Plastic Design of Frames, Vols. 1 and 2, Cambridge University Press.

14. Ewins, D. (2000). Modal testing: theory, practice and application. Baldock, Hertfordshire, England, Research Studies Press LTD.

15. Cosenza, E. and G. Manfredi (2000). "Damage indices and damage measures." Progress in Structural Engineering and Materials 2(2): 50-59.

16. Mendes, N., Lourenço, P.B. and Campos-Costa, A. (2013). Shaking table testing of an existing masonry building: assessement and improvement of the seismic performance. Earthquake Engineering \& Structural Dynamics 43(2): 247-266.

17. Lemaitre, J. and Desmorat, R. (2005). Engineering damage mechanics: Ductile, creep, fatigue and brittle failures, Springer. 